\title{
RESEARCH
}

Open Access

\section{Identification of lymphocyte cell-specific protein-tyrosine kinase (LCK) as a driver for invasion and migration of oral cancer by tumor heterogeneity exploitation}

Jonas Weiße ${ }^{1}$, Julia Rosemann ${ }^{1 \dagger}$, Lisa Müller ${ }^{2 \dagger}$, Matthias Kappler ${ }^{3}$, Alexander W. Eckert ${ }^{4}$, Markus Glaß ${ }^{5}$, Danny Misiak ${ }^{5}$, Stefan Hüttelmaier ${ }^{5}$, Wolfgang G. Ballhausen ${ }^{6}$, Mechthild Hatzfeld ${ }^{2}$, Monika Haemmerle ${ }^{7}$ and Tony Gutschner ${ }^{1 *}$ (D)

\begin{abstract}
Background: Cancer metastases are the main cause of lethality. The five-year survival rate for patients diagnosed with advanced stage oral cancer is 30\%. Hence, the identification of novel therapeutic targets is an urgent need. However, tumors are comprised of a heterogeneous collection of cells with distinct genetic and molecular profiles that can differentially promote metastasis making therapy development a challenging task. Here, we leveraged intratumoral heterogeneity in order to identify drivers of cancer cell motility that might be druggable targets for anti-metastasis therapy.
\end{abstract}

Methods: We used 2D migration and 3D matrigel-based invasion assays to characterize the invasive heterogeneity among and within four human oral cancer cell lines in vitro. Subsequently, we applied mRNA-sequencing to map the transcriptomes of poorly and strongly invasive subclones as well as primary tumors and matched metastasis.

Results: We identified SAS cells as a highly invasive oral cancer cell line. Clonal analysis of SAS yielded a panel of 20 subclones with different invasive capacities. Integrative gene expression analysis identified the Lymphocyte cellspecific protein-tyrosine kinase (LCK) as a druggable target gene associated with cancer cell invasion and metastasis. Inhibition of LCK using A-770041 or dasatinib blocked invasion of highly aggressive SAS cells. Interestingly, reduction of LCK activity increased the formation of adherens junctions and induced cell differentiation.

Conclusion: Analysis of invasive heterogeneity led to the discovery of LCK as an important regulator of motility in oral cancer cells. Hence, small molecule mediated inhibition of LCK could be a promising anti-metastasis therapy option for oral cancer patients.

Keywords: Clonal heterogeneity, Dasatinib, EMT, HNSCC, Invasion, ITH, Metastasis, OSCC, SrC

\footnotetext{
* Correspondence: tony.gutschner@uk-halle.de

†Julia Rosemann and Lisa Müller contributed equally to this work.

'Junior Research Group 'RNA biology and pathogenesis', Faculty of Medicine,

Martin Luther University Halle-Wittenberg, 06120 Halle, Germany

Full list of author information is available at the end of the article
}

C C The Author(s). 2021 Open Access This article is licensed under a Creative Commons Attribution 4.0 International License, which permits use, sharing, adaptation, distribution and reproduction in any medium or format, as long as you give appropriate credit to the original author(s) and the source, provide a link to the Creative Commons licence, and indicate if changes were made. The images or other third party material in this article are included in the article's Creative Commons licence, unless indicated otherwise in a credit line to the material. If material is not included in the article's Creative Commons licence and your intended use is not permitted by statutory regulation or exceeds the permitted use, you will need to obtain permission directly from the copyright holder. To view a copy of this licence, visit http://creativecommons.org/licenses/by/4.0/ The Creative Commons Public Domain Dedication waiver (http://creativecommons.org/publicdomain/zero/1.0/) applies to the data made available in this article, unless otherwise stated in a credit line to the data. 


\section{Background}

Oral cancers of the lip, tongue and oral cavity were estimated to account for $\sim 355,000$ newly diagnosed neoplasia and over 177,000 cancer deaths in 2018 [1, 2]. Oral squamous cell carcinomas (OSCC), a subgroup of head and neck squamous cell carcinoma (HNSCC), account for more than $90 \%$ of all oral cancers. Distinct phenotypes are differentiated in the oral mucosa depending on their environment. Whereas the gingival epithelium constitutes of a stratified squamous keratinized epithelium, the oral sulcular epithelium appears to be stratified and non-keratinized [3]. OSCC can originate from altered stem cells or through dedifferentiation of early-stage differentiated cells $[4,5]$. Well-known risk factors of oral cancer are tobacco and alcohol abuse, consumption of areca nut products as well as infection with human papilloma virus (HPV) [6-8]. Several genetic and epigenetic alterations that lead to genomic instability and loss of tumor suppressor genes (TP53, CDKN2A, RB1, RBL1/2) as well as activation of oncogenic signaling pathways including epithelial growth factor receptor (EGFR), phosphatidylinositol-3-kinase (PI3K)/AKT/mammalian target of rapamycin (mTOR), mitogen-activated protein kinase (MAPK), and Janus kinase/signal transducers and activators of transcription (JAK/STAT) have been associated with oral cancer $[9,10]$. Despite significant advances in the diagnosis and treatment of oral cancers, the identification of novel therapeutic targets is an urgent need given the 5 -year survival rate of $\sim 30 \%$ for patients with advanced disease $[11,12]$. Once patients develop distant metastases, the median time to death is only 3.3 months [13]. Thus, thorough investigations of the mechanisms involved in oral cancer metastasis are needed to develop effective therapeutics to extend the life of patients. However, our current understanding of the underlying molecular processes is still very limited and druggable targets involved in the metastatic dissemination of oral cancer cells are yet to be revealed. Importantly, the invasion-metastasis cascade is a multistep process including several steps that have to be taken by tumor cells in order to spread from the primary tumor site to a distant location [14]. It starts with cells detaching from the primary tumor and locally breaching through the basement membrane in order to invade the surrounding extracellular matrix and connective tissue. Upon intravasation into the blood or lymphatic vessels cancer cells travel to distant anatomical sites where they extravasate from the vessels and invade into the stroma of the metastatic site. Here, the tumor cells form micrometastases and eventually start their proliferative program in order to colonize the tissue. Importantly, phenotypic plasticity markedly influences the metastatic progression, as it enables tumor cells to tolerate and adapt to several different stress factors and changing environments [15-17]. An important source of plasticity of malignancy is epithelial-to-mesenchymal transition (EMT), an epigenetically controlled program that enables transitions between different phenotypic states that confer motility and enhance survival [5]. EMT is associated with a loss of cell adhesiveness and polarity as well as cytoskeletal and signaling changes thereby enhancing the ability of cancer cells to migrate and invade. The underlying regulatory mechanisms have been extensively studied and a critical role for EMT along the metastatic cascade has been described in several cancer entities including oral cancers $[18,19]$. However, some controversies regarding the relevance of EMT exist and alternative mechanisms of migration should be considered, also in conjunction with EMT, to capture the full spectrum of cell states, which is a prerequisite to develop effective anti-metastasis strategies [20,21]. Another important aspect that needs to be considered is tumor heterogeneity. Heterogeneity exists on multiple levels: in between different patients of the same tumor entity (inter-tumoral heterogeneity), between metastasis of the same patient (inter-metastatic heterogeneity) or among the cells of one tumor (intra-tumoral heterogeneity, ITH). ITH is a key factor for drug resistance and metastasis formation [22]. In HNSCC and especially OSCC patients, a high ITH was described by several studies [23-25]. Clonal heterogeneity accelerates metastasis dissemination by increasing the probability for invasive subclones. Here, we reasoned that pre-existing ITH within oral cancer cell populations could be exploited not only to gain a deeper understanding of the molecular mechanisms of metastasis, but also to identify important and potentially druggable target genes. By isolating individual subclones of a highly invasive oral cancer cell line, we identified the Lymphocyte cell-specific protein-tyrosine kinase (LCK) as an important regulator of migration and invasion. Inhibition of LCK using a clinically approved drug, i.e. dasatinib, induced cancer cell differentiation and impaired cell motility by enhancing the formation of adherens junctions. Hence, LCK might be a promising target that should be further evaluated in pre-clinical and clinical studies in the future.

\section{Methods}

Cell culture, subclone generation, and drug treatments

The human squamous cell carcinoma cell lines $\mathrm{FaDu}$ (hypopharynx), Cal33 (oral tongue), XF354 (oral cavity) and SAS (oral tongue) were a kind gift of Prof. Daniel Zips and have been cultured in RPMI-1640 medium supplemented with $10 \%$ fetal bolvine serum (FBS), 100 Units $/ \mathrm{ml}$ penicillin, $100 \mu \mathrm{g} / \mathrm{ml}$ streptomycin (Thermo Fisher Scientific, Waltham), $2 \mathrm{mML}$-Glutamine and 1 $\mathrm{mM}$ sodium pyruvate (Sigma Life Science, St. Louis) at $37^{\circ} \mathrm{C}$ and $5 \% \quad \mathrm{CO}_{2}$. SAS subclones were randomly 
isolated (no selection/surface marker) via single cell sorting into 96 well plates filled with culture medium containing $2.5 \mu \mathrm{g} / \mathrm{ml}$ amphotericin B using a FACS Melody device (BD Bioscience, New Jersey). A total of twenty subclones were further cultivated and used in subsequent experiments. For chemical LCK inhibition, cells were treated with dasatinib (Sigma-Aldrich, St. Louis) or A-770041 (Axon Medchem, Reston) as indicated.

\section{Three-dimensional sphere growth and matrigel invasion}

$10^{3}$ cells were seeded in $50 \mu \mathrm{l}$ cell culture medium in an ultra-low attachment 96 well plate (Corning, New York), centrifuged at $300 \mathrm{~g}$ for $6 \mathrm{~min}$. After $24 \mathrm{~h}, 50 \mu \mathrm{l}$ cell culture medium was added and cells were centrifuged for 6 min at $300 \mathrm{~g}$ again. The sphere area was measured immediately and after $48 \mathrm{~h}$. For invasion assays, cells were imbedded in $50 \mu \mathrm{l}$ matrigel (Corning, New York) centrifuged at $300 \mathrm{~g}, 4^{\circ} \mathrm{C}$ for $6 \mathrm{~min}$. The matrigel was solidified for $30 \mathrm{~min}$ at $37^{\circ} \mathrm{C}$ and picture were taken every $6 \mathrm{~h}$ for a total of $48 \mathrm{~h}$ using an IncuCyte S3 (Essen Bioscience, Goettingen). For the initial characterization of twenty subclones pictures were taken every hour to determine the starting time of invasive growth. Additionally, the invasion area was measured after $48 \mathrm{~h}$. Both values were combined in the invasion factor which was calculated as follows:

$$
I F_{\text {cloneX }}=\frac{A_{\text {cloneX }}+e^{-\frac{250 \times t_{\text {cloneX }}}{1119}+\frac{86539}{44760}}}{2}
$$

IF - invasion factor, A - invasion area, $\mathrm{t}$ - starting time of invasive growth.

The formula was created via a logarithmic regression of the starting time of the invasive growth and the invasive growth area $\left(R^{2}=0.611\right)$.

\section{Wound closure migration assay}

$5 \times 10^{4}$ cells were cultured in $100 \mu \mathrm{l}$ medium in a 96well-plate overnight. Using the sterilized 96-pin IncuCyte WoundMaker Tool (Essen Bioscience, Goettingen), a wound was scratched into the cell monolayer. Every 4 $\mathrm{h}$ a picture was taken for $24 \mathrm{~h}$. The wound density was calculated with the IncuCyte software. The slope (\% / h) until reaching $100 \%$ was regressed using GraphPad Prism software 8.0 (GraphPad Software, San Diego).

\section{Zymography for MMP activity}

Total protein of $24 \mathrm{~h}$ preconditioned medium was concentrated using Pierce ${ }^{\mathrm{Tm}}$ Protein concentrators (cut off $10 \mathrm{~K}$ MWCO, Thermo Fisher Scientific, Waltham) and solubilized via RIPA lysis buffer $(50 \mathrm{mM}$ Tris- $\mathrm{HCl} \mathrm{pH}$ 8.0, $150 \mathrm{mM} \mathrm{NaCl}, 1 \%$ (v/v) IGEPAL CA-630, 0.5\% (w/v) Na-deoxycholate, $0.1 \%(\mathrm{w} / \mathrm{v}) \mathrm{SDS}) .15 \mu \mathrm{g}$ protein was loaded on a gelatine containing zymogram gel
(Invitrogen, Carlsbad). After $30 \mathrm{~min}$ incubation in renaturation buffer (2.5\% Triton-X100), the gel was developed overnight in zymogram developing buffer (Thermo Fisher Scientific, Waltham) at $37^{\circ} \mathrm{C}$. Protein standard bands were measured before coomassie G-250 (Carl Roth, Karlsruhe) staining. After staining, the gel was analyzed using an Odyssey infrared scanner (LICOR, Lincoln).

\section{Western blot}

$1.5 \times 10^{6}\left(8 \times 10^{5}\right)$ cells were seeded in $10 \mathrm{~cm}(6 \mathrm{~cm})$ plates. A rubber policeman was used to harvest cells gently. The cells were washed in PBS (Thermo Fisher Scientific, Waltham) and lysed in RIPA lysis buffer (50 $\mathrm{mM}$ Tris- $\mathrm{HCl} \mathrm{pH} 8.0,150 \mathrm{mM} \mathrm{NaCl}, 1 \%$ (v/v) IGEPAL CA-630, 0.5\% (w/v) Na-deoxycholate, 0.1\% (w/v) SDS) supplemented with protease and phosphatase inhibitor cocktail (Roche, Basel). After SDS-Page and wet blot, protein abundance was evaluated via Odyssey infrared scanner (LICOR). Primary antibodies for Rpl7 (A300741A, Bethyl, Montgomery), Vinculin (sc-25,336, SantaCruz, Dallas), E-cadherin (\#3195S), Vimentin (\#5741S), Lck (\#2984 T, all Cell Signaling, Danvers), p(Y118)-Paxillin (MAB6164), and Paxillin (MAB4259, both R\&D Systems, Minneapolis) and $\mathrm{p}(\mathrm{Y} 118)$-Paxillin (Supplementary Fig. S4, 44-722G, Thermo Fisher Scientific, Waltham) were used.

RNA isolation and reverse transcription-quantitative polymerase chain reaction (RT-qPCR)

$1.5 \times 10^{6}$ cells were seeded in $10 \mathrm{~cm}$ plates and total RNA was isolated $48 \mathrm{~h}$ later using an acid guanidinium thiocyanate-phenol-chloroform extraction method [26]. The RNA pellet was washed and resuspended in ultrapure water (Life Technologies, Carlsbad). For cDNA synthesis $2 \mu \mathrm{g}$ total RNA was reverse transcribed using random hexamer primers and the M-MLV Reverse Transcriptase system (Promega, Madison). Gene expression was measured using primaQuant CYBR-qPCRMastermix (Steinbrenner Laborsysteme, Wiesenbach) and a Light Cycler I (Roche, Basel). RPLP0, PPIA, and POLR2A were used as reference genes. Sequence information for qPCR primers are listed in Table 1 below:

\section{mRNA-sequencing and differential gene expression}

mRNA-sequencing was performed with $2 \mu \mathrm{g}$ of RNA $(n=3)$ for each sample: library prep and sequencing was performed by Genewiz (Leipzig, Germany). Library prep was based on poly-A-tail selection; sequencing was performed on an Illumina NovaSeq platform resulting in 20 million reads per sample. Raw data was quality checked ( $80 \%$ bases $\mathrm{Q} \geq 30)$ and trimmed via Trim Galore! v0.4.3.1. The Reads were mapped via RNA STAR v2.6.0b-2 to human genome hg38. The differential gene 
Table 1 List of RT-qPCR primers used in this study

\begin{tabular}{|c|c|c|}
\hline target & direction & sequence $\left(5^{\prime}>3^{\prime}\right)$ \\
\hline MMP1 & forward & TGTGAGGCGGTAGTAGGACA \\
\hline MMP1 & reverse & TTGTCCCGATGATCTCCCCT \\
\hline MMP2 & forward & CCAAGTGGTCCGTGTGAAGT \\
\hline MMP2 & reverse & GCCGTACTTGCCATCCTTCT \\
\hline ITGB1 & forward & GGTTGCCCTCCAGATGACAT \\
\hline ITGB1 & reverse & AAATGTCTGTGGCTCCCCTG \\
\hline FN1 & forward & GAGCTGAGTGAGGAGGGAGA \\
\hline FN1 & reverse & CAGGCGCTGTTGTTTGTGAA \\
\hline ING4 & forward & AAAGGCCGGACTCAAAAGGA \\
\hline ING4 & reverse & CACATCAGAGGGGTGGACAC \\
\hline $\mathrm{CDH} 1$ & forward & CGGGAATGCAGTTGAGGATC \\
\hline $\mathrm{CDH} 1$ & reverse & AGGATGGTGTAAGCGATGGC \\
\hline $\mathrm{CDH} 2$ & forward & AAGTGGCAAGTGGCAGTAAAAT \\
\hline $\mathrm{CDH} 2$ & reverse & CCAGTCTCTCTTCTGCCTITGT \\
\hline VIM & forward & ATGCGTGAAATGGAAGAGAACT \\
\hline VIM & reverse & TGTAGGTGGCAATCTCAATGTC \\
\hline LAPTM5 & forward & GCTACCTCAGGATCGCTGAC \\
\hline LAPTM5 & reverse & GGGAACTTGGAGGAGCTAGC \\
\hline LCK & forward & GACAGCATTCACCAGGACCA \\
\hline LCK & reverse & ATGTAGATGGGCTCCTGGGT \\
\hline SERPINB2 & forward & GGTGAGAAGTCTGCGAGCTT \\
\hline SERPINB2 & reverse & GACAGCATTCACCAGGACCA \\
\hline RPLPO & forward & GGCGACCTGGAAGTCCAACT \\
\hline RPLPO & reverse & CCATCAGCACCACAGCCTTC \\
\hline PPIA & forward & GTCAACCCCACCGTGTTCTT \\
\hline PPIA & reverse & CTGCTGTCTTTGGGACCTTGT \\
\hline POLR2A & forward & CTTGCCCCGTGCCATGCAGA \\
\hline POLR2A & reverse & CTCGCACCCGGCCTTCCTTG \\
\hline
\end{tabular}

expression analysis was performed according to edge $\mathrm{R} \mathrm{v}$ 3.24.1 usage. Statistical overrepresentation test was performed with the Panther database platform (http:// pantherdb.org/).

\section{Reverse small interfering RNA (siRNA) transfection}

Transfection reagent (RNAiMax, Thermo Fisher Scientific, Waltham) and siRNAs were mixed and then incubated in Opti-MEM (Thermo Fisher Scientific, Waltham) medium for 5 min. $6 \times 10^{5}$ cells were seeded in 6 well-plates in antibiotics-free medium. The transfection mix was added drop wise resulting in a final siRNA concentration of $15 \mathrm{nM}$. The following siRNAs targeting human LCK were used: siLCK1 (5' - UUCGUAGGUA ACCAGUGGGdTdT-3') and siLCK2 (5'- UUUCCA UCCAGUCAUCUUCdTdT-3').
Immunofluorescence analysis and image processing

SAS cells grown on poly-L-lysine $(0.5 \mathrm{mg} / \mathrm{ml})$-coated coverslips were fixed for $10 \mathrm{~min}$ (p120, Plakophilin 4, $\beta$ catenin) in methanol at $-20^{\circ} \mathrm{C}$, permeabilized in detergent buffer (100 mM PIPES (pH 6.9), $4 \mathrm{M}$ glycerol, $2 \mathrm{mM}$ EDTA, $1 \mathrm{mM}$ EGTA, 0.5\% (v/v) Triton X-100) for 15 $\mathrm{min}$ at RT and blocked in $1 \%(\mathrm{w} / \mathrm{v}) \mathrm{BSA} / \mathrm{PBS}$ for $30 \mathrm{~min}$ at RT. For co-staining of E-cadherin and F-actin, cells were fixed for $20 \mathrm{~min}$ in $3.7 \%(\mathrm{w} / \mathrm{v})$ formaldehyde in PBS at $4{ }^{\circ} \mathrm{C}$, permeabilized in detergent buffer for $15 \mathrm{~min}$ at RT and blocked in 1\% (w/v) BSA/PBS for $30 \mathrm{~min}$ at RT. Primary antibodies for E-cadherin (13-1900, Invitrogen), $\beta$-catenin (610154), p120 (610,134, both BD Bioscience, New Jersey), and Plakophilin 4 (651,166, Progen) were diluted in blocking solution and incubated overnight at $4{ }^{\circ} \mathrm{C}$ in a humid chamber. After washing with PBS, coverslips were briefly blocked in blocking solution and incubated for $1 \mathrm{~h}$ at RT with the fluorophore-conjugated secondary antibody. DNA was stained with Hoechst 33342 (Thermo Fisher Scientific, Waltham). F-actin was visualized using Alexa Fluor 568 Phalloidin (Invitrogen, Carlsbad). Coverslips were mounted in Mowiol (Calbiochem, San Diego). Images were acquired on a confocal microscope (Leica SP8X) equipped with a white light laser, HyD detectors using a $63 x / 1.40$ oil objective and Leica LAS AF software (Leica Microsystems, Wetzlar, Germany). ImageJ 1.52r [27] was used for image processing. To determine the enrichment factors for protein localization at lateral contacts, fluorescence intensities were measured in segments of equal length (about 150 px) and width (20 px) covering the cytoplasm as well as bicellular contacts as previously described [28]. The enrichment factors were calculated by dividing the mean junctional value (10 px length of the 150 px scan line) by the mean cytoplasmic value (both ends of a scan line, each 10 px length) for a total of 500 individual measurements. All calculated enrichment factors are shown as violin plots displaying the full distribution of the data.

\section{Correlation of LCK expression with the metastatic potential of cancer cell lines}

LCK and SRC mRNA expression data (RNA-Seq) across 1019 human cancer cell lines were downloaded from the Cancer Cell Line Encyclopedia (CCLE) data portal (https://portals.broadinstitute.org/ccle) [29]. The metastatic potential of 488 human cancer cell lines, including 21 cell lines of the upper aerodigestive tract, was recently mapped [30]. Respective data were downloaded from https://pubs.broadinstitute.org/metmap. Absolute expression values of LCK and SRC were correlated with the metastatic potential of each cell line using Pearson correlation in GraphPad Prism software 8.0 (GraphPad Software, San Diego). Significance was tested using a two-tailed t-test. 


\section{Immunohistochemical analysis}

LCK expression in paraffin-embedded OSCC tissues from four patients was analyzed using a 1:200 dilution of a monoclonal rabbit anti-Lck antibody (\#2984S, Cell Signaling, Danvers) according to the manufacturer's recommendations.

\section{Correlation of LCK expression with clinical data}

Analysis of expression and association of LCK with clinical parameters (tumor stage, grade, nodal status) within the TCGA HNSC dataset was done using the UALCAN web resource [31]. Its association with patient survival and HNSCC subtypes was retrieved from the GEPIA2 portal [32]. Patient information and expression data for OSCC subgroup analysis were obtained from cBioPortal using the TCGA Firehose Legacy dataset [33-35].

\section{Statistical analysis}

For all data, the mean and its standard derivations are reported. Comparisons of two groups were analyzed using unpaired two-tailed Student's t-test. Multiple comparisons were run using one-way ANOVA, grouped data respectively with two-way ANOVA, and corrected via Dunnett's test. All statistical analyses were performed using GraphPad Prism software 8.0 (GraphPad Software, San Diego) and the difference was considered significant when $p<0.05$ (* $p<0.05$; * $p<0.01$; *** $p<0.001)$. Experiments were repeated at least three times, except Zymography experiments, which were performed in biological duplicates.

\section{Results}

\section{HNSCC-derived cell lines show differences in their} invasive capacity

In order to characterize the invasive behavior of head and neck cancer cell lines in vitro, we applied a threedimensional (3D) matrigel-based invasion assay. Initially, four HNSCC cell lines, namely SAS (oral tongue), FaDu (hypopharynx), Cal33 (oral tongue), and XF354 (oral cavity) were analyzed. While FaDu, Cal33 and XF354 did not grow invasive in our experimental setting, SAS cells exhibited a highly invasive phenotype suggesting a strong intercellular heterogeneity among these squamous cell carcinoma lines (Fig. 1A). To gain first insights into the underlying molecular differences of cellular invasiveness, we analyzed the activity of matrix metalloproteinase 2 (MMP2), a key enzyme responsible for extracellular matrix (ECM) degradation thereby enhancing cancer cell dissemination [36]. Using a zymographic assay we were able to detect active MMP2 in the supernatant of all four cell lines (Fig. 1B). Surprisingly, the non-invasive cell line XF354 showed nearly twice as much MMP2 activity as the strongly invasive SAS cell line suggesting that matrix-degrading activity alone could not explain the observed differences in the invasive potential of the HNSCC-derived cell lines. Hence, we analyzed additional factors that had been closely linked with cancer invasion. In many tumors, integrins and their downstream signaling as well as EMT have been shown to play a crucial role in motility and invasiveness $[18,37]$. However, besides some differences in the transcript levels of ITGB1, FN1, MMP1 and MMP2 among the four cell lines, no clear association was identified (Supplementary Fig. 1A). The same was true for the expression of EMT-related genes. For example, the epithelial cell adhesion protein E-cadherin $(C D H 1)$ was expressed in all four cell lines with the highest level in XF354 and the lowest expression in FaDu and SAS cells (Supplementary Fig. 1B, C). In contrast, the expression of the mesenchymal cell adhesion gene $\mathrm{N}$-cadherin $(\mathrm{CDH} 2)$ was lowest in XF354 and highest in SAS indicating a cadherin switch in SAS cells, which has been associated with a higher motility and invasiveness and is often observed during an EMT [38]. However, Vimentin, another marker of EMT and commonly found in mesenchymal cells was well expressed in both, invasive (SAS) and non-invasive (XF354) cells (Supplementary Fig. 1B, C).

Taken together, our initial matrigel-based invasion assay revealed a heterogeneous capacity of HNSCC-derived cell lines to invade the extracellular matrix, which cannot be explained solely by the observed expression differences of well-established invasion-associated genes nor the activity of matrix-degrading enzymes like MMP2. Importantly, these analyses also identified SAS cells as a suitable model system to study squamous cancer cell invasion.

\section{Exploiting intratumoral heterogeneity to isolate SAS subclones with different invasion characteristics} In earlier studies, the OSCC-derived SAS cell line had been shown to be comprised of a heterogeneous population of cells that differ in their invasive potential [39]. We reasoned that the clonal heterogeneity could be leveraged to gain insights into the molecular mechanisms that contribute to the invasive phenotype of these cells. Therefore, we generated 20 SAS subclones via single cell sorting (Fig. 1C). After expansion, the clones were thoroughly analyzed and differences in their invasion dynamics and overall matrigel infiltration were recorded. To quantify and visualize both observations for each clone individually, we calculated an invasion factor, which combined the invasion start time as well as the relative invasion area, and plotted the relative invasiveness of each clone, i.e. the respective invasion factor normalized to the average of all clones (Fig. 1D). This analysis uncovered five clones $(\mathrm{C}, \mathrm{H}, \mathrm{K}, \mathrm{M}, \mathrm{S})$ that were more invasive, and five clones $(\mathrm{D}, \mathrm{F}, \mathrm{L}, \mathrm{Q}, \mathrm{T})$ that where less 


\section{a}
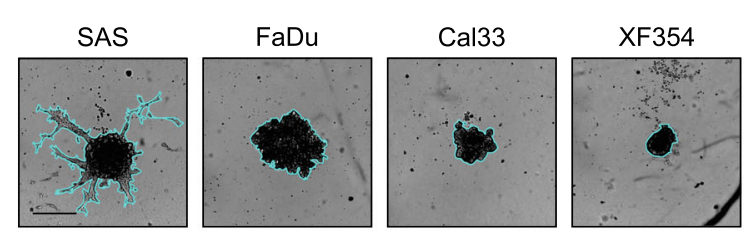

c

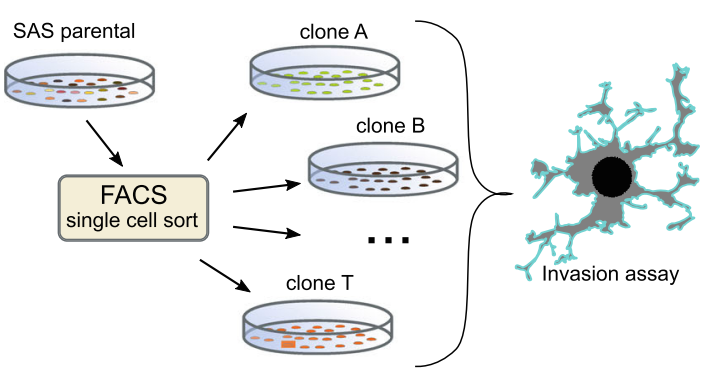

e
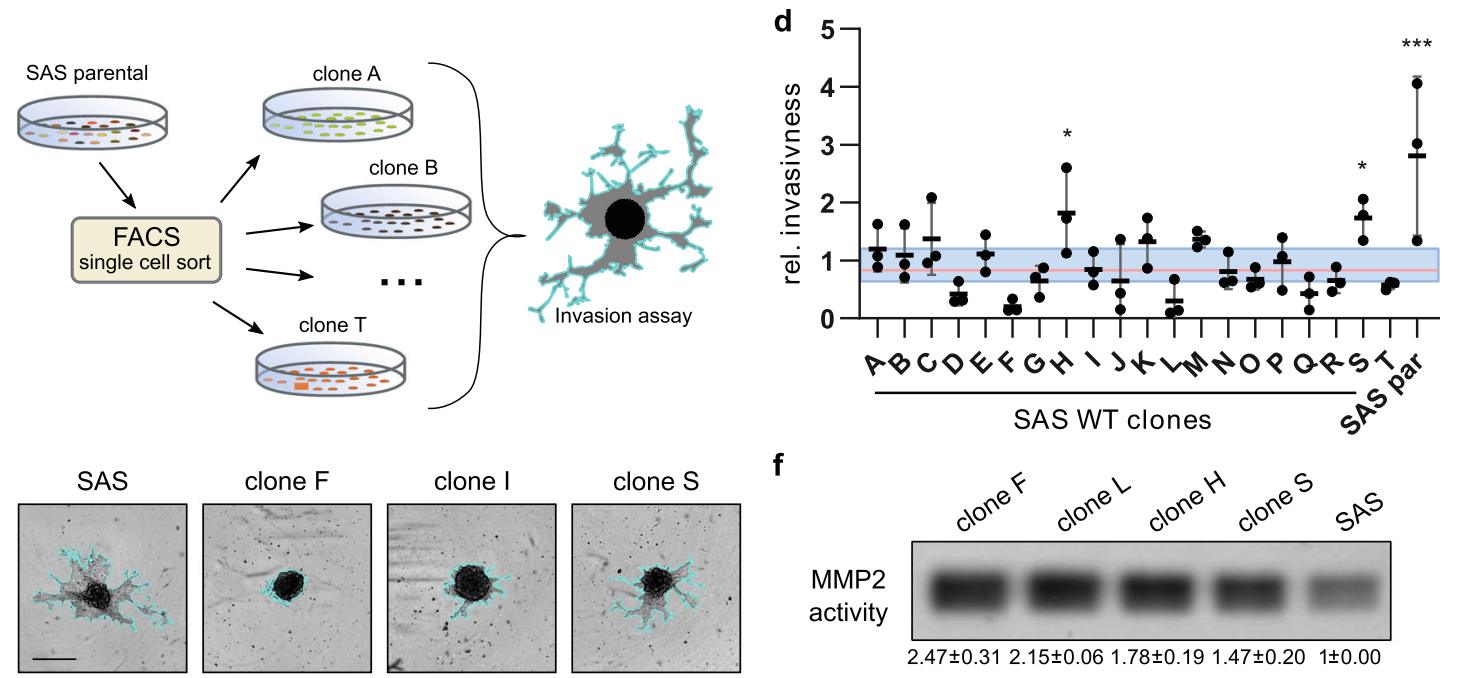

g
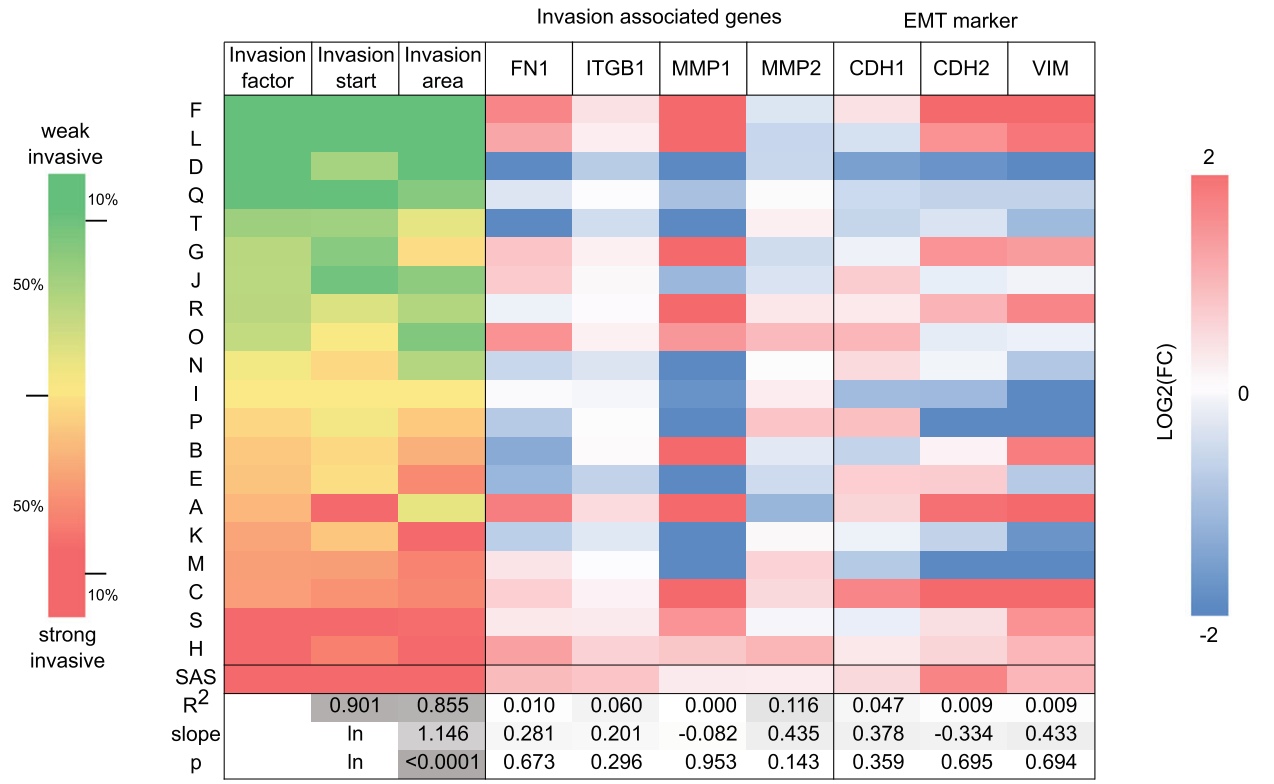

h

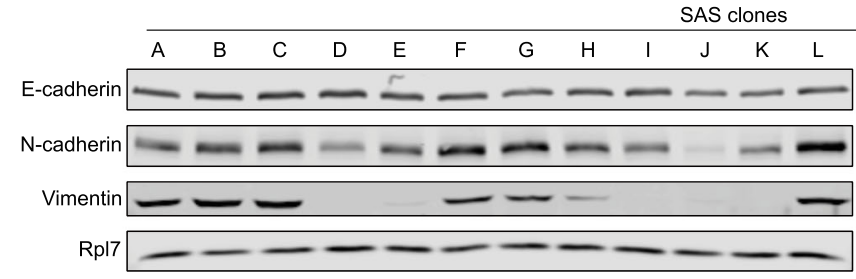
Invasion factor

Fig. 1 (See legend on next page.) 


\begin{abstract}
(See figure on previous page.)
Fig. 1 HNSCC-derived cell lines show a high inter- and intratumoural invasive heterogeneity. A 3D matrigel invasion assays were performed using SAS, FaDu, Cal33 and XF354. Pictures were taken after $48 \mathrm{~h}$. The invasive front is marked in turquoise (scale bar $=400 \mu \mathrm{m}, n=3$ ). B Proteins of preconditioned media of the HNSC cell line panel were concentrated and loaded onto a gelantine containing zymogram gel. Reduced Coomassie G-250 staining intensity indicates the activity of MMP2 ( 70 kDa; $n=2)$. C Flow chart of SAS subclone generation. D 3D matrigel invasion assay was performed with twenty SAS subclones as well as the parental SAS cell line and their relative invasiveness is displayed. Here, the invasion factor of each clone was normalized to the average of all clones. The median is shown with a red line, second and third quartiles are displayed with a blue box. One-way ANOVA was performed comparing each clone with all clones of the second and third quartiles $\left(n=3 ;{ }^{*} p<\right.$ $\left.0.05,{ }^{* *} p<0.01,{ }^{* * *} p<0.001\right)$. E Pictures (48 h) showing parental SAS and representative subclones with a low, median and high invasiveness. The invasion front is marked in turquoise (scale bar $=400 \mu \mathrm{m}$ ). F MMP2 activity was measured via zymogram in the subclones with the weakest ( $F$ \& $\mathrm{L})$ and highest ( $\mathrm{H} \& \mathrm{~S})$ invasiveness as well as the parental cell line $(n=2)$. G Clones were ranked according to their invasion factor from weak (top, green) to strongly invasive (bottom, red). Expression of invasion associated genes and EMT markers in each clone were measured via RTqPCR and normalized to RPLPO, PPIA as well as the average expression in all clones $(n=3)$. High relative expression of a gene is indicated by a red color, whereas blue indicates a low relative expression. Expression values were correlated with the invasion factor. Correlation coefficient $R^{2}$, the slope of the regression curve and the significance value $\mathrm{p}$ of the slope being non-zero of a correlation analysis to the invasion factor are shown. Since the invasion start correlates in a logarithmic manner to the invasion area, values of the slope are marked with "In". H Representative Western blot $(n=3)$ of the epithelial marker E-cadherin and the mesenchymal markers $\mathrm{N}$-cadherin and Vimentin in relation to the invasion factor. Rpl7 served as loading control
\end{abstract}

invasive than the average. The parental SAS cell line showed the highest invasiveness (Fig. 1E). We again performed a zymographic assay and compared the two most invasive clones $(\mathrm{H}, \mathrm{S})$ with the two least invasive ones $(\mathrm{F}$, L). However, we could not detect differences in MMP2 activities that would explain the observed phenotypes. Instead, weak invasive clones even seemed to possess higher MMP2 activity than the strongly invasive ones (Fig. 1F). Nevertheless, to gain additional insights into potential pathways that might be involved in functionally regulating the motility of these clones, we analyzed the expression of the same invasion and EMT-associated genes as before (see Supplementary Fig. 1) using RTqPCR and correlated their relative expression levels in all 20 clones with the invasion capacity of the respective clone (Fig. 1G). However, the expression patterns of these seven genes did not correlate well with the invasive phenotype $\left(p>0.14 ; \mathrm{R}^{2}<0.12\right)$. This was further confirmed on protein level by analysis of E-cadherin, $\mathrm{N}$ cadherin and Vimentin expression, which failed to provide a clear link to the invasive phenotype (Fig. 1H). In detail, the epithelial marker E-cadherin was commonly detected in all clones, whereas the mesenchymal markers Vimentin and $\mathrm{N}$-cadherin were differentially expressed with high levels in weak as well as strongly invasive subclones. To quantify this observation, we calculated the Vimentin / E-cadherin as well as the $\mathrm{N}$-cadherin / Ecadherin ratios for each clone and correlated it to the invasion factor, which yielded a poor correlation in both cases (Supplementary Fig. 2A). Interestingly, the 20 subclones split into two groups with different mesenchymal characteristics, i.e. Vim ${ }^{\text {high }} / \mathrm{N}-$ cad $^{\text {high }}$ and $\mathrm{Vim}^{\text {low }} / \mathrm{N}$ $\mathrm{Cad}^{\text {low }}$, yet no correlation with the invasion factor was observed (Supplementary Fig. 2B). Thus, the epithelialmesenchymal differentiation status of the individual clones seemed to be a poor predictor of their invasive properties.
Integrative gene expression analysis identifies LCK as a putative driver of invasiveness and metastasis in OSCC In order to identify genes and signaling pathways that could provide a molecular explanation for the invasion phenotypes of SAS subclones, we performed mRNAsequencing and compared gene expression pattern between the two most $(\mathrm{H}, \mathrm{S})$ and the two least invasive subclones (F, L). This analysis identified a total of 756 significantly $(\mathrm{FDR}<0.05)$ deregulated genes of which 561 showed an increased and 195 a decreased expression in the invasive subclones $\mathrm{H}$ and $\mathrm{S}$ (Fig. 2A, B). The 10 most increased as well as 10 most decreased genes together with their $\log 2 \mathrm{FC}$ and FDR are summarized in Fig. 2C. To further narrow down the list of putative invasion-associated genes we also analyzed the transcriptomes of nine pairs of primary OSCC tumors and their matched metastasis (lymph node). This differential expression analysis yielded a total of 687 genes (FDR < 0.05 ) with 479 being higher expressed and 208 genes being downregulated in metastasis (Fig. 2D, E). The 20 most differentially expressed genes in terms of log2FC are listed in Fig. 2F. To systemically examine altered intracellular signaling pathways and biological processes we performed a statistical overrepresentation test with all significantly deregulated genes from both analyses separately using the gene ontology website (http:// geneontology.org). We grouped the significantly overrepresented biological processes into six groups: immune response, cell morphology/migration, Rho/G protein signaling, neuronal, metabolism and other. As expected, biological processes related to the immune response as well as cell morphology/migration were enriched in lymph node metastasis, whereas invasive subclones showed an enrichment for neuronal and metabolic processes as well as cell morphology/migration-associated gene sets (Fig. 2G). Finally, we integrated both expression datasets and searched for individual genes that 

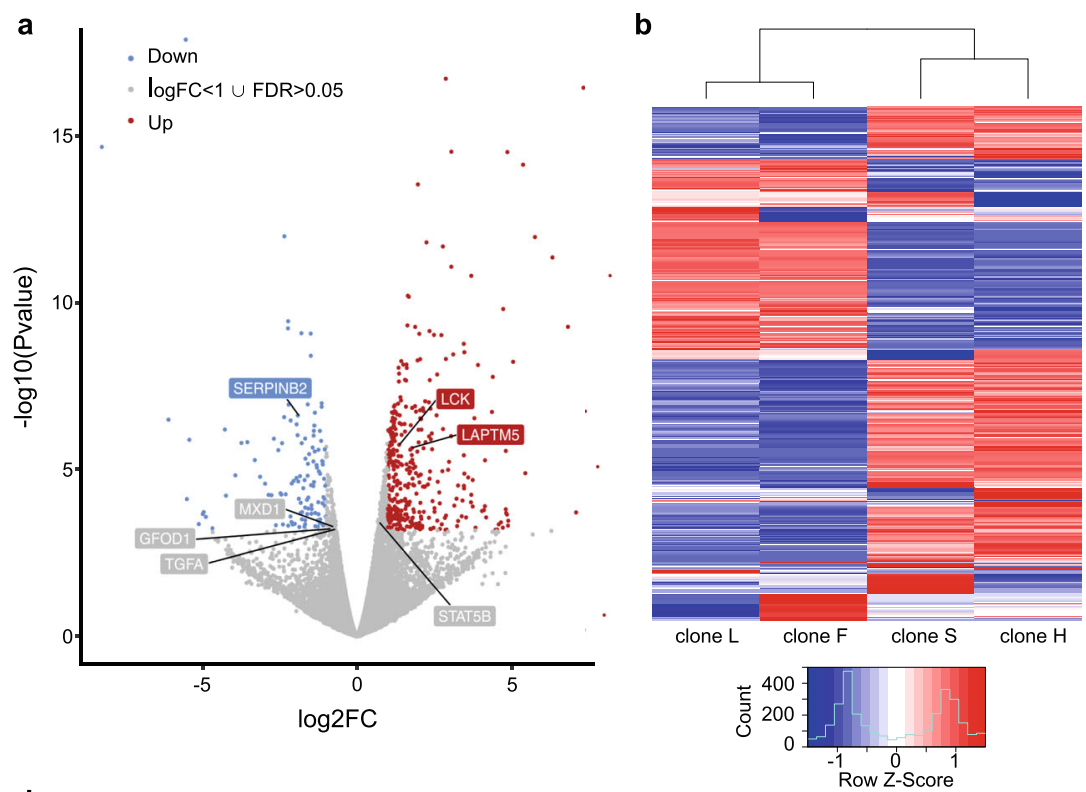

c

d

e
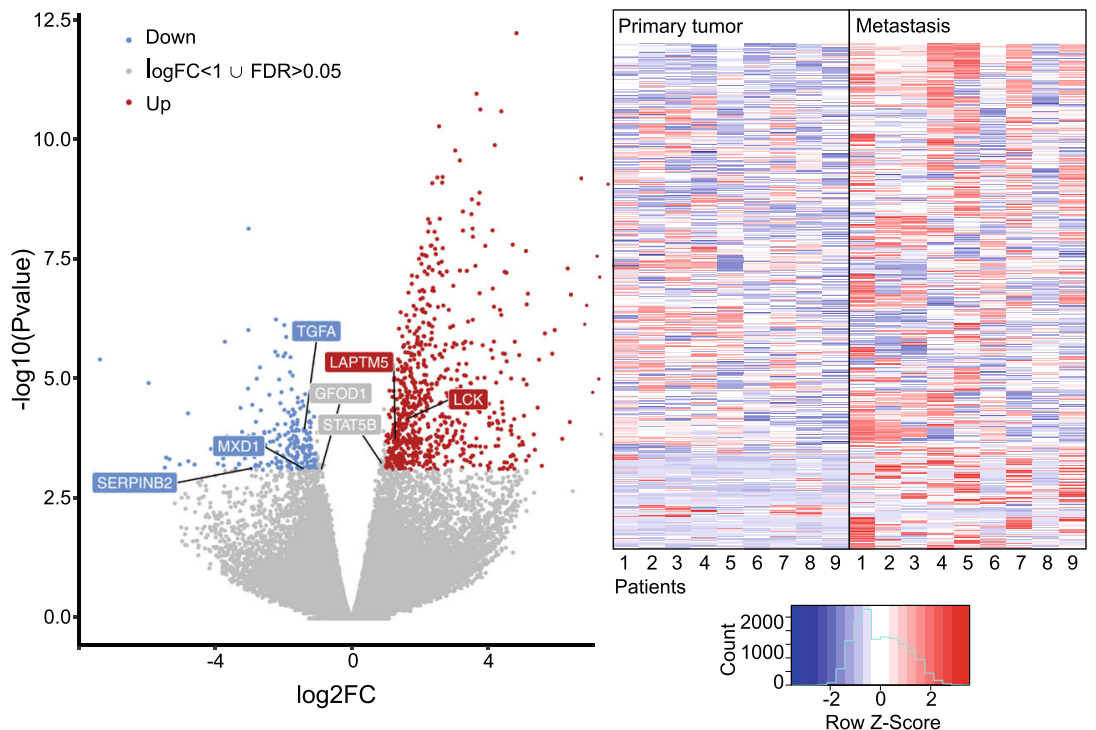

\begin{tabular}{|l|c|c|}
\hline Gene Symbol & log2FC & FDR \\
\hline SLC16A7 & 7,31 & $7,10 \mathrm{E}-13$ \\
\hline BGN & 7,07 & $2,25 \mathrm{E}-02$ \\
\hline PRAC2 & 6,81 & $1,41 \mathrm{E}-06$ \\
\hline AC006050.2 & 6,31 & $1,98 \mathrm{E}-08$ \\
\hline CBFA2T3 & 5,74 & $6,32 \mathrm{E}-09$ \\
\hline SOSTDC1 & 5,43 & $3,17 \mathrm{E}-03$ \\
\hline MYO15B & 5,36 & $6,13 \mathrm{E}-11$ \\
\hline MAG & 5,04 & $9,09 \mathrm{E}-06$ \\
\hline ARHGEF15 & 4,88 & $3,27 \mathrm{E}-02$ \\
\hline G0S2 & 4,87 & $4,13 \mathrm{E}-02$ \\
\hline CDC20B & $-4,65$ & $4,65 \mathrm{E}-02$ \\
\hline RP11-70C1.1 & $-4,86$ & $2,76 \mathrm{E}-02$ \\
\hline RNVU1-19 & $-4,93$ & $2,21 \mathrm{E}-02$ \\
\hline RP4-764D2.1 & $-4,96$ & $2,43 \mathrm{E}-02$ \\
\hline RFPL4AL1 & $-5,09$ & $3,88 \mathrm{E}-02$ \\
\hline RBP4 & $-5,40$ & $5,83 \mathrm{E}-04$ \\
\hline TMPRSS15 & $-5,48$ & $1,21 \mathrm{E}-02$ \\
\hline RP11-366L20.2 & $-5,51$ & $7,72 \mathrm{E}-14$ \\
\hline STXBP6 & $-6,07$ & $2,16 \mathrm{E}-04$ \\
\hline C50rf60 & $-8,22$ & $2,99 \mathrm{E}-11$ \\
\hline
\end{tabular}

f

\begin{tabular}{|l|c|c|}
\hline Gene Symbol & log2FC & FDR \\
\hline FDCSP & 5,166 & $1,33 \mathrm{E}-04$ \\
\hline CR2 & 5,111 & $3,35 \mathrm{E}-05$ \\
\hline IGHV3-43 & 4,914 & $1,10 \mathrm{E}-03$ \\
\hline MS4A1 & 4,834 & $3,44 \mathrm{E}-08$ \\
\hline FCRL1 & 4,541 & $6,20 \mathrm{E}-05$ \\
\hline PAX5 & 4,391 & $3,72 \mathrm{E}-07$ \\
\hline TCL1A & 4,138 & $1,21 \mathrm{E}-03$ \\
\hline IGHV3-11 & 3,847 & $8,00 \mathrm{E}-04$ \\
\hline FCRL3 & 3,777 & $3,72 \mathrm{E}-07$ \\
\hline BANK1 & 3,756 & $5,31 \mathrm{E}-06$ \\
\hline HEPHL1 & $-2,994$ & $1,82 \mathrm{E}-05$ \\
\hline SERPINB13 & $-3,011$ & $3,60 \mathrm{E}-03$ \\
\hline CNFN & $-3,101$ & $3,53 \mathrm{E}-02$ \\
\hline SPRR2D & $-3,186$ & $1,53 \mathrm{E}-02$ \\
\hline PI3 & $-3,228$ & $6,89 \mathrm{E}-03$ \\
\hline SPRR2A & $-3,687$ & $7,50 \mathrm{E}-04$ \\
\hline CALB1 & $-3,726$ & $4,37 \mathrm{E}-02$ \\
\hline CRNN & $-5,307$ & $3,64 \mathrm{E}-02$ \\
\hline UPK1B & $-5,914$ & $2,92 \mathrm{E}-03$ \\
\hline MUC21 & $-7,340$ & $1,28 \mathrm{E}-03$ \\
\hline
\end{tabular}

g

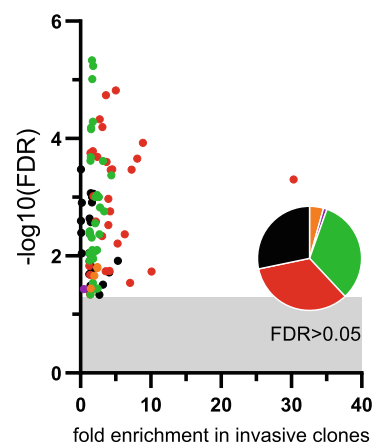

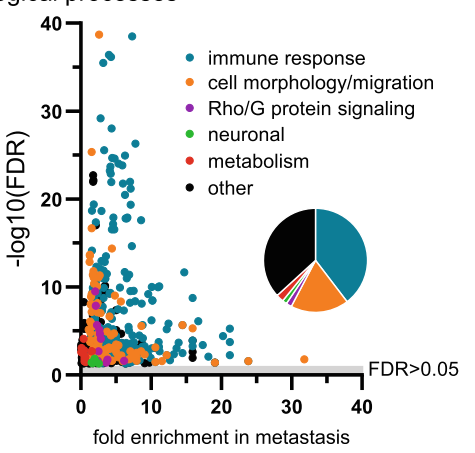

h

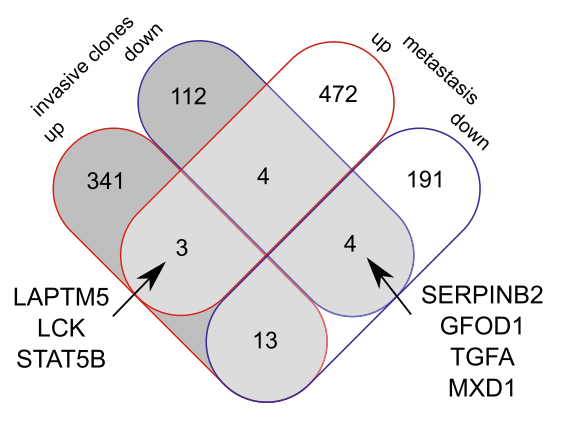

Fig. 2 (See legend on next page.) 


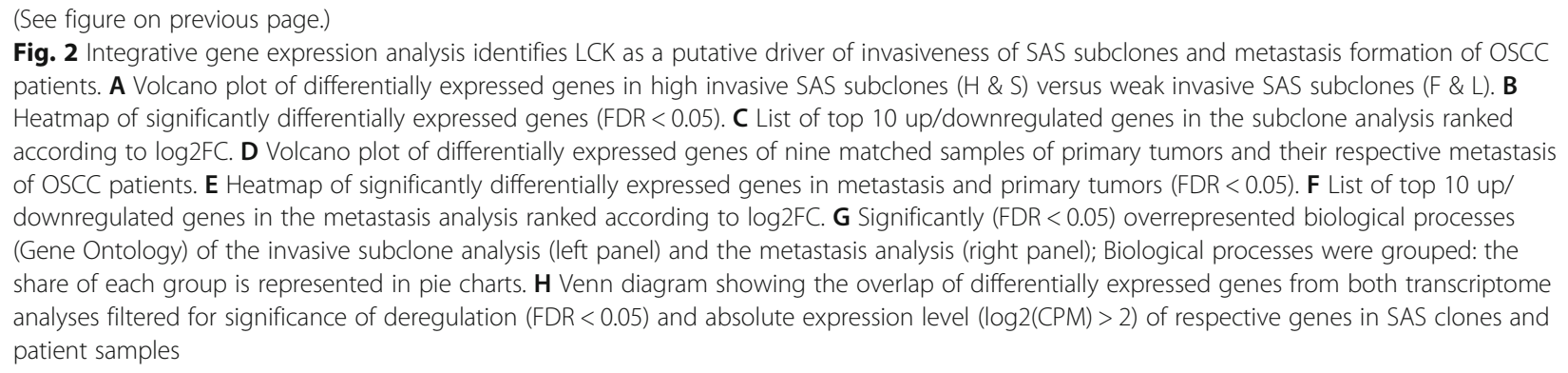

showed the same trend of regulation $(\mathrm{FDR}<0.05)$ in both conditions as well as an absolute expression level of $\log 2$ (counts per million mapped reads $(\mathrm{CPM}))>2$ to filter for lowly expressed genes. This analysis retrieved three genes, namely LAPTM5, LCK, and STAT5B that were upregulated in metastasis as well as in highly invasive subclones (Fig. 2H). Moreover, four genes (SERP INB2, GFOD1, TGFA, MXD1) were downregulated in these samples suggesting an inhibitory role in oral cancer cell invasion and metastasis. Among the seven overlapping genes LAPTM5, LCK and SERPINB2 showed the strongest fold change $(\log 2 \mathrm{FC}>1)$ in both analyses. LAPTM5 encodes a lysosomal protein transmembrane transporter, which was shown to be involved in hematopoiesis [40]. Its relevance for tumor cell invasion was initially investigated in bladder cancer cells and a positive effect of LAPTM5 on proliferation as well as migration and invasion was revealed [41]. In contrast, a recent study identified LAPTM5 as an inhibitor of clonogenicity and invasiveness of CD40-positive glioblastoma cells [42]. SERPINB2 encodes a serine protease inhibitor also known as PAI-2 (plasminogen activator inhibitor type-2) and has a context-dependent role in human cancers. For example, in vivo experiments with breast cancer cell lines revealed a pro-metastatic function of SERPINB2 [43], whereas the opposite was shown for lung cancer cells [44]. In line with this, overexpression of SERPINB2 in nasopharyngeal carcinoma cells also decreased invasiveness suggesting a tumor suppressive role in human head and neck cancers [45]. LCK belongs to the Src family of tyrosine kinases and has been best studied in the context of $\mathrm{T}$-cell function and signaling as well as lymphocytic leukemia of the B-cell lineage [46]. In addition, LCK expression was also detected in a number of solid cancers including breast, colon and lung cancers. In breast cancer, LCK was shown to enhance or suppress cell motility and invasiveness in a contextdependent manner [47-49]. Intriguingly, inhibition of LCK reduced the formation of pseudopodia and the migration of glioma cells in a human glioma cell-axonoligodendrocyte co-culture model [50]. Moreover, LCK was shown to be a major regulator of cytoskeletal dynamics, migration and myelination in the peripheral nervous system through its impact on $\beta 1$-integrin signaling in Schwann cells [51].

Since LCK is a druggable enzyme, we focused on this non-receptor tyrosine kinase to more closely investigate its biological role and target potential in the context of oral cancer cell migration, invasion and metastasis.

\section{LCK regulates SAS cell migration in vitro}

First, we performed RT-qPCR and detected a higher overall LCK mRNA expression in 12 metastasis samples as compared to 117 primary OSCC tumors thereby confirming the mRNA-sequencing results (Fig. 3A). Moreover, analysis of our initial HNSCC cell line panel detected the highest LCK transcript and protein level in the invasive SAS cell line (Fig. 3B-D). At the level of SAS subclones LCK expression was more variable (Fig. $3 E)$. However, the two highly invasive subclones $C$ and $S$ (invasion factor rank 2 and 3, see Fig. 1G) also showed the highest LCK abundance. Interestingly, LCK mRNA as well as protein expression strongly and significantly correlated with the invasion factor specifically in the $\mathrm{Vim}^{\text {high }} / \mathrm{N}$-cad ${ }^{\text {high }}$ subgroup of clones (Fig. $3 \mathrm{~F}$ and Supplementary Fig. 3A, B), which further supports the idea that LCK is an important factor of oral cancer cell motility. To more directly investigate the role of LCK in this context, we performed loss-of-function analyses using two independent siRNAs that successfully reduced LCK protein levels in two invasive clones $(\mathrm{H}, \mathrm{S})$ as well as in parental SAS cells (Fig. 3G, H). Importantly, transient knockdown of LCK reduced the motility of both subclones as well as the parental cell line as analyzed by a 2D wound closure assay (Fig. 3I, J). These findings suggest that LCK is indeed actively involved in regulating cell autonomous mechanisms of oral cancer cell motility.

\section{Chemical inhibition of LCK suppresses the invasive phenotype}

To further investigate the targeting potential of LCK, we took advantage of readily available small molecule tyrosine kinase inhibitors (TKIs), namely A-770041 and dasatinib. A-770041, herein called LCKi, is a highly specific LCK TKI (specificity over other Src family kinases: 


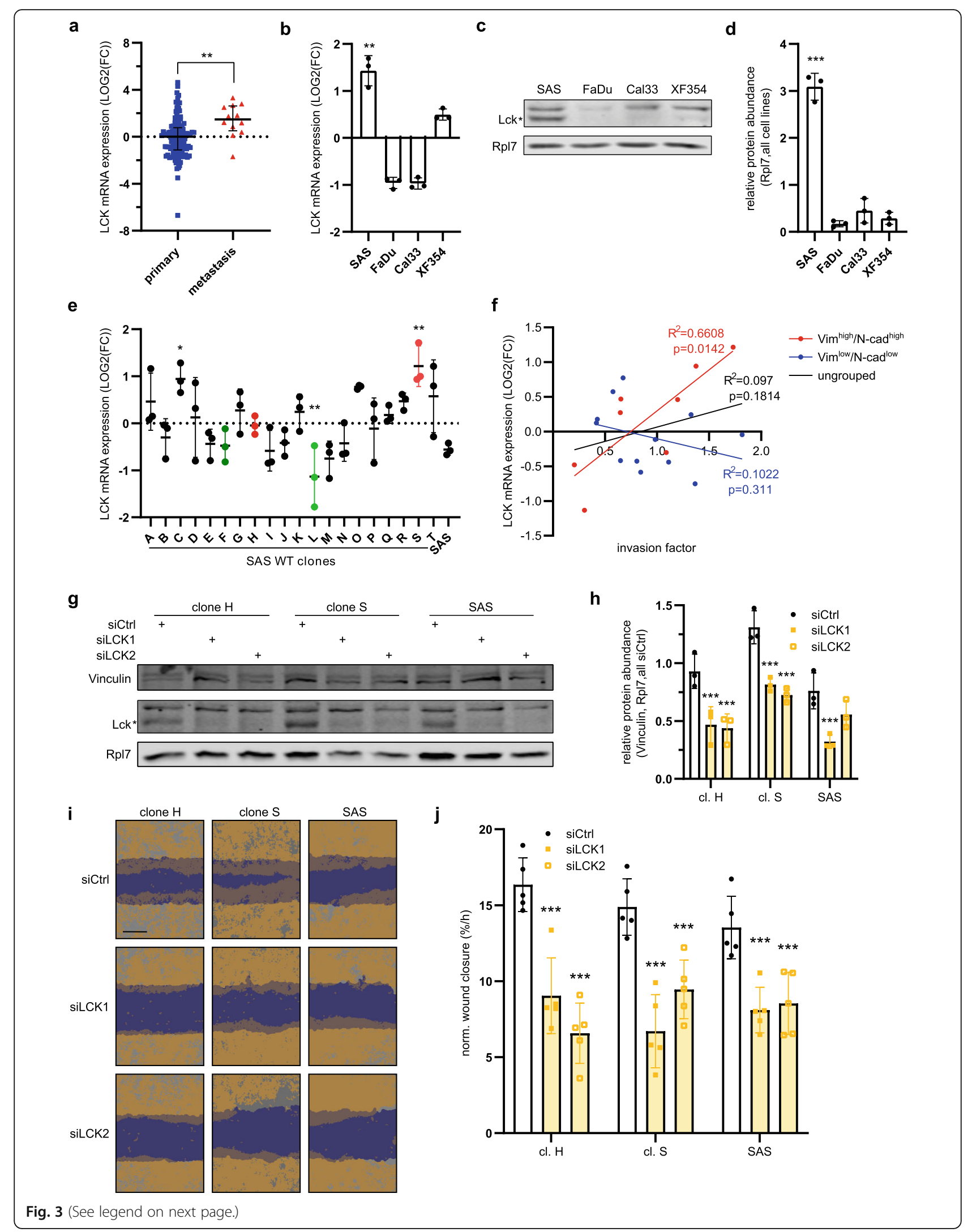




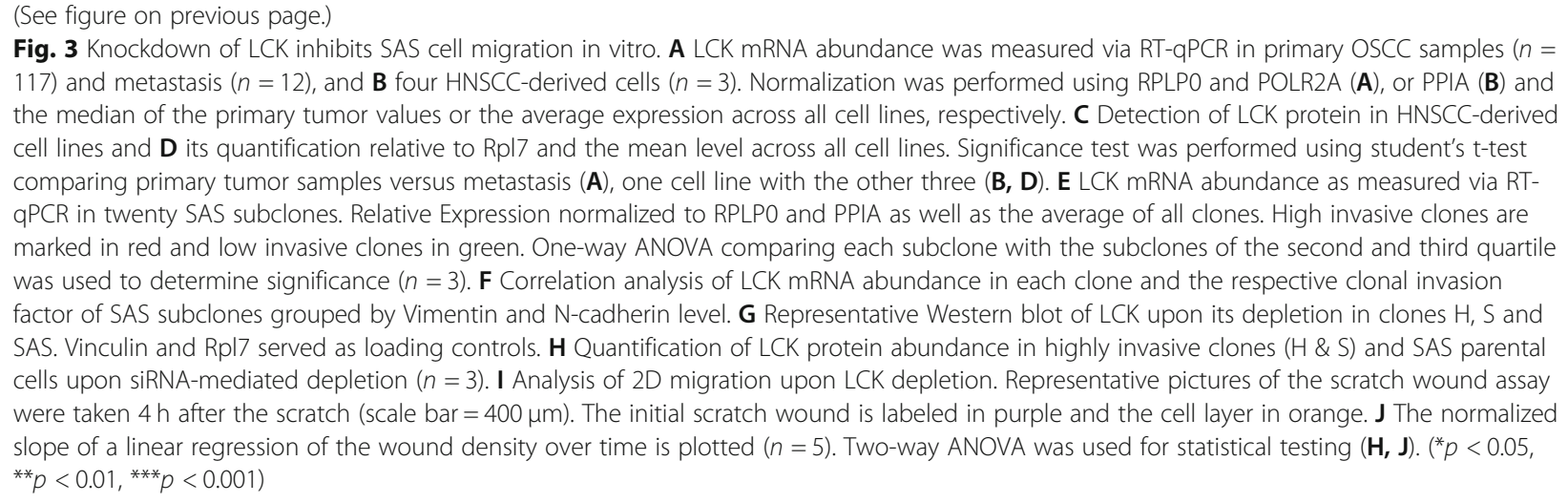

300-fold over Fyn, >60-fold selectivity versus $\mathrm{Src}$ and Fgr, and $>8$-fold versus Lyn and Hck) with a half maximal inhibitory concentration (IC50) of $147 \mathrm{nM}[52,53]$. In contrast, dasatinib is an orally active dual BCR-ABL and broad Src family tyrosine kinase inhibitor (IC50: 0.4 $\mathrm{nM}$ LCK; $0.5 \mathrm{nM}$ for Src and Yes) that is FDA-approved and currently indicated for the treatment of Philadelphia chromosome-positive $(\mathrm{Ph}+)$ chronic myeloid leukemia (CML) and $\mathrm{Ph}+$ acute lymphoblastic leukemia (ALL) [54]. Importantly, treatment of the highly invasive subclones $\mathrm{H}$ and $\mathrm{S}$ as well as parental SAS cells with LCKi $(500 \mathrm{nM})$ or dasatinib $(100 \mathrm{nM})$ immediately after creating a wound scratch strongly decreased two-dimensional cell motility (Fig. 4A). While LCKi treatment significantly slowed down the process of wound closure, dasatinib treatment fully prevented it (Fig. 4B). Of note, both drugs effectively inhibited the migration of $\mathrm{FaDu}$, Cal33 and XF354 cells as well (Supplementary Fig. 4A-D). Furthermore, both TKIs robustly inhibited SAS cell invasion in a three-dimensional matrigel-based assay (Fig. 4C, D). Importantly, both inhibitors did not interfere with spheroid formation and had only minor, insignificant effects on three-dimensional growth at the concentrations used in invasion and migration assays (Fig. 4E, F). Mechanistically, Zepecki et al. suggested that, in glioblastoma cells, the reduced cell motility after LCK inhibition would be due to a decreased phosphorylation of Paxillin on tyrosine 118 resulting in a reduced turnover of focal adhesions [50]. Therefore, we analyzed total Paxillin as well as its Y118 phosphorylation status in TKI treated SAS cells. Surprisingly, the total protein amount of Paxillin was highly increased after LCKi treatment, and even more so after application of dasatinib (Fig. 4G). This increase was not caused by an upregulation of Paxillin mRNA (mRNA-Seq, data not shown). On the other hand, the amount of Y118 phosphorylated Paxillin remained stable. Consequently, the cellular proportion of Y118-phosphorylated Paxillin was strongly decreased after LCKi and dasatinib treatment (Fig. 4H).
Of note, highly invasive SAS cells as well as invasive subclones $\mathrm{H}$ and $\mathrm{S}$ showed an increased phosphorylation status of Paxillin under steady-state conditions as compared to non-invasive cell lines and clones (Supplementary Fig. 4E, F). Hence, LCK inhibition might suppress motility and invasiveness of SAS cells through a reduction of focal adhesion dynamics.

\section{LCK knockdown and inhibition induces cornification of SAS cells}

To better understand the subsequent downstream effects of LCK signaling inhibition, we performed mRNAsequencing after siRNA-mediated LCK depletion as well as LCKi and dasatinib treatment of SAS parental cells. In detail, transient LCK depletion significantly changed the expression of 402 (241 up, 161 down, FDR $<0.05$ ) genes. In contrast, small molecule inhibitor treatment significantly altered the expression of 219 (LCKi; 136 up, 83 down) and 313 (dasatinib; 169 up, 144 down) genes, respectively. We reasoned that those genes that might be involved in regulating LCK-dependent cell motility would show an inverse regulation in the invasive clones or the patient-derived metastasis samples. Hence, we combined our gene expression analyses and filtered for genes that were significantly deregulated in at least three out of five datasets (Fig. 5A). Additionally, we computed a LCK correlation score (LCS) which would increase, if the gene was regulated in the same direction after LCK knockdown and chemical inhibition, while at the same time the gene was inversely regulated in metastasis and highly invasive clones. We used this score to further filter and sort the gene list (Fig. 5A). Importantly, we identified four genes, namely LAPTM5, LPXN, ETV4, and $K I F 21 B$, which were significantly upregulated in invasive clones and/or metastasis while at the same time showing a significant downregulation after LCK knockdown and/ or inhibitor treatment (Fig. 5B). On the other hand, nine genes were downregulated in invasive clones and/or metastasis, but upregulated upon LCK depletion and/or 
a

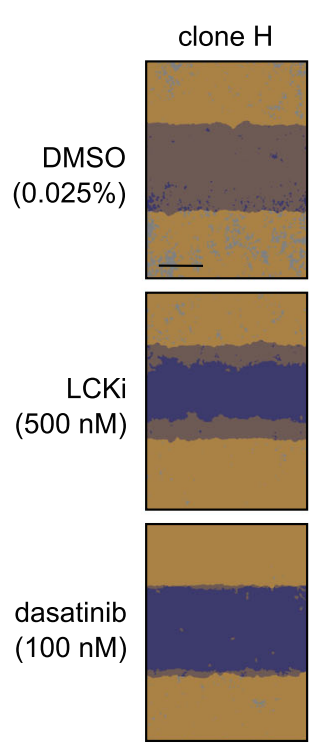

C

DMSO

(0.025\%)
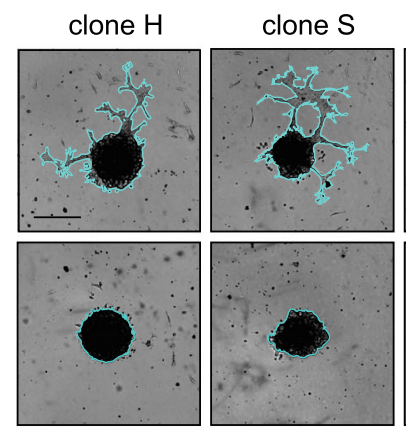

e

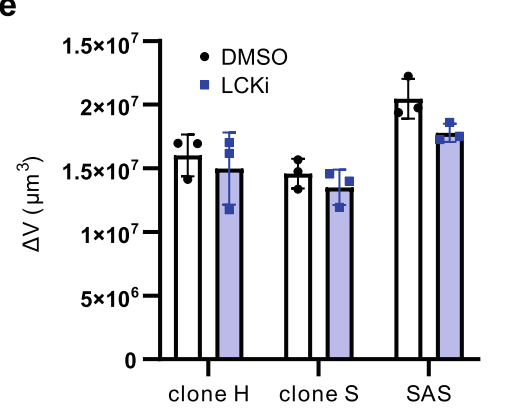

g

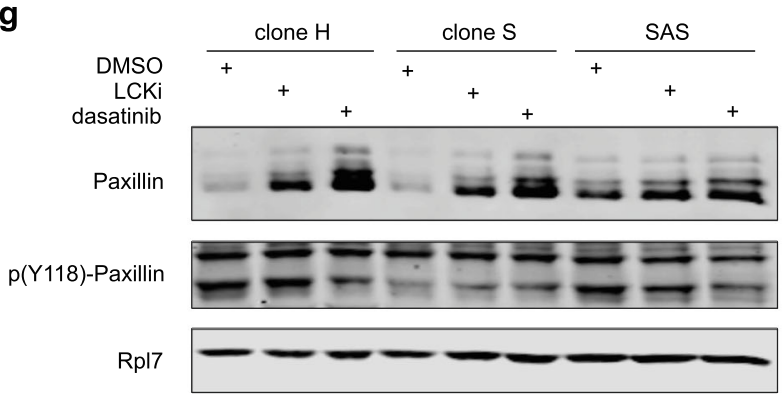

b

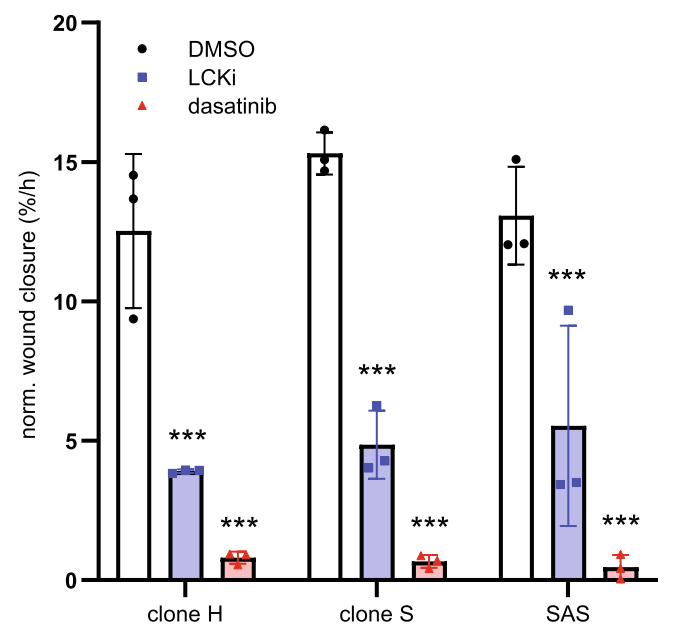

d

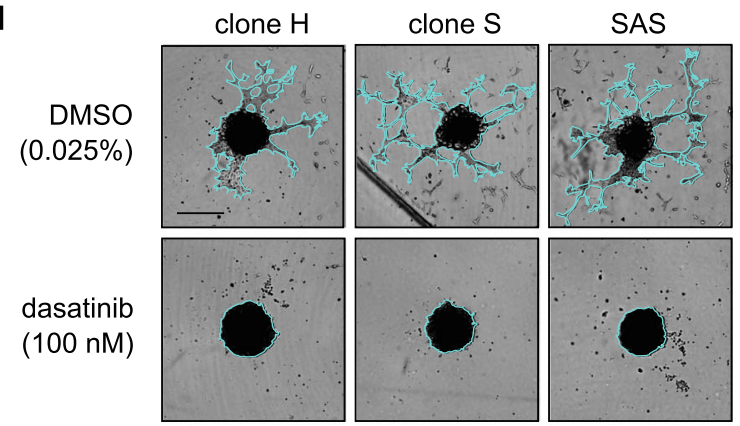

f
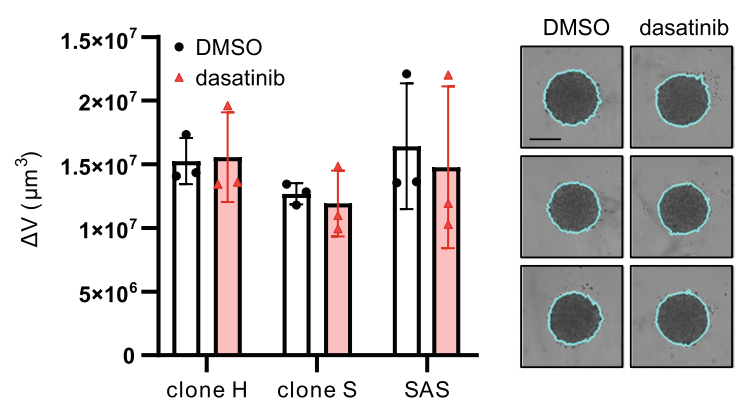

h

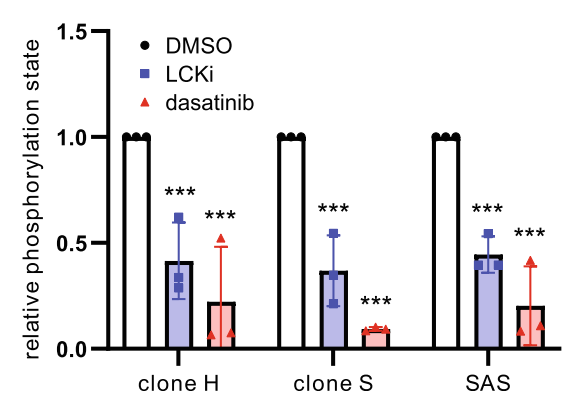

Fig. 4 (See legend on next page.) 


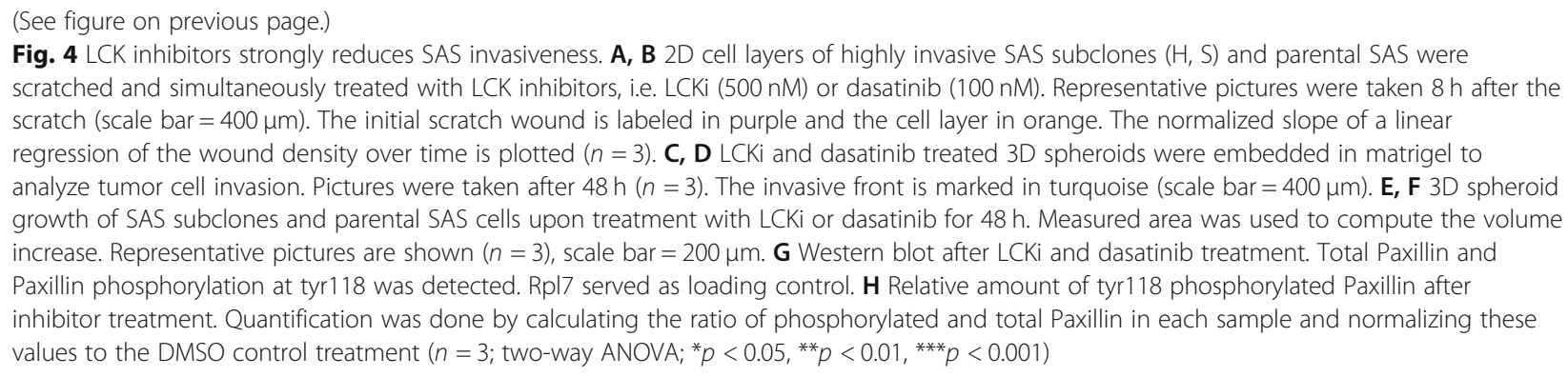

inhibition (Fig. 5C). Interestingly, the cancer genome atlas (TCGA) HNSCC RNA expression dataset revealed a positive correlation between $L C K$ and LAPTM5, $K I F 21 B$ and $L P X N$, as well as negative expression correlation of LCK with TGM1, KRT14 and KRT17 further supporting the idea that these genes are regulated by LCK signaling in oral cancer cells (Supplementary Fig. 5A). Next, we asked whether LCK-dependent gene expression changes could be assigned to specific biological processes. Hence, we performed a gene ontology analysis using the candidate lists of differentially expressed genes upon LCK knockdown (402 genes), LCKi (219 genes) and dasatinib (313 genes) treatments. We filtered for biological processes that were significantly overrepresented ( $>3$-fold) in at least two analyses. Intriguingly, epithelial differentiation, especially stratification (including cornification and keratinization) were identified as biological downstream processes regulated by LCK (Fig. 5D). We utilized the superpathway "keratinization" (https://pathcards.genecards.org/) and checked for significantly deregulated genes in our five mRNA-sequencing analyses. Intriguingly, several genes of this superpathway including genes from the epidermal differentiation complex (SPRR2A, SPRR2D, SPRR2F, $S P R R 1 B, I V L)$ were downregulated in metastasis/invasive clones and/or upregulated upon LCK knockdown/inhibition (Fig. 5E). Subsequent RT-qPCR analyses confirmed the impact of LCK on the expression of LAPTM5, LPXN and the differentiation associated genes TGM1, KRT14, and KRT17 (Fig. 5F), as well as on KIF21B, KRT5 and CTSV transcript levels (Supplementary Fig. 5B).

Taken together, our integrative gene expression analyses suggest a critical role for LCK in preventing the differentiation of OSCC cells by repressing the expression of differentiation-associated genes.

\section{LCK inhibition leads to an accumulation of E-cadherin at lateral cell-cell contacts and induces the formation of adherens junctions}

A main aspect of epithelial differentiation and stratification is the strengthening of cell-cell contacts, which is essential for barrier formation. Adhesive contacts comprise adherens junctions (AJ) that associate with actin filaments and desmosomes connected to keratin filaments. De novo formation of desmosomes is initiated at AJs and thus depends on these structures. Moreover, the loss of E-cadherin expression occurs frequently during tumor metastasis. Therefore, we decided to investigate the formation of AJs more closely. Immunofluorescence co-stainings of E-cadherin revealed an increase of cellcell contacts after knockdown or inhibition of LCK (Fig. 6A, B). In control treated SAS cells (siCtrl, DMSO), E-cadherin, the major transmembrane protein of epithelial AJs, localized mainly to the cytoplasm with some punctate cell-cell contacts along the lateral membranes. Treatment with siLCK1, siLCK2, LCKi or dasatinib led to a strong accumulation of E-cadherin at cell-cell contacts and induced continuous lateral AJs (see Fig. 6A (left panel), Fig. 6B). Since clustering and stabilization of E-cadherin depends on catenins that mediate the attachment of actin filaments, we analyzed whether the changes observed in E-cadherin localization correlated with changes in F-actin organization (Fig. 6A (middle panel), Fig. 6B). Indeed, knockdown or inhibition of LCK led to a reorganization of the actin cytoskeleton resulting in cortical F-actin localization. Importantly, extensive co-localization of E-cadherin and F-actin was observed at lateral membranes after LCK knockdown or inhibition (Fig. 6A, right panel). Of note, E-cadherin protein, but not mRNA (Supplementary Fig. 5C), was slightly and significantly increased after LCK knockdown and inhibition potentially due to its stabilization in cellcell contacts (Fig. 6C). Since the connection between Ecadherin and F-actin in AJs depends on the cytoplasmic catenins, we asked whether these proteins also displayed altered localization patterns. Immunostainings of the anchor proteins $\beta$-catenin, p120-catenin and Plakophilin 4 further supported the effect of LCK knockdown and inhibition on the formation of AJs in SAS cells (Supplementary Fig. 6A, B). In siCtrl and DMSO treated cells, $\beta$-catenin, p120 as well as Plakophilin 4 showed only a weak lateral membrane localization. In contrast, treatment with siLCK1, siLCK2, LCKi or dasatinib enhanced their localization at bicellular contacts. Thus, LCK knockdown promoted $\mathrm{AJ}$ formation as indicated by the accumulation of E-cadherin, $\beta$-catenin, p120-catenin and 


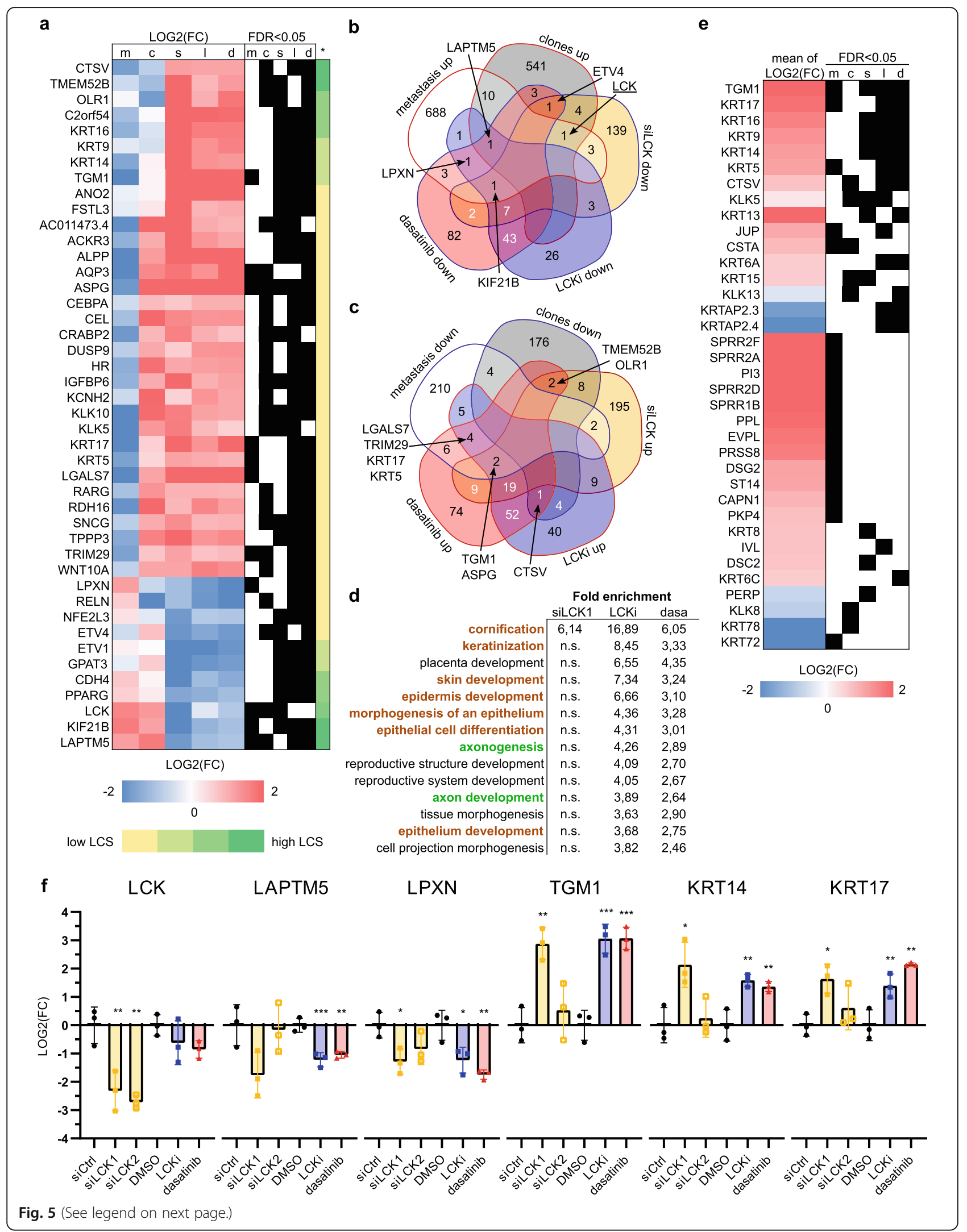




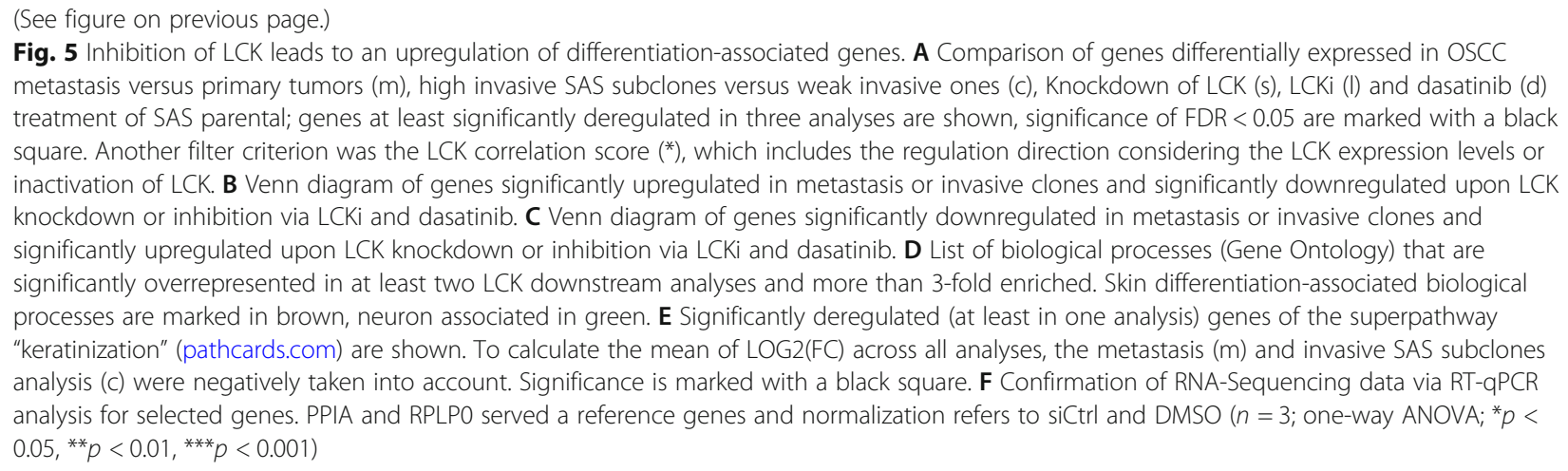

Plakophilin 4 at lateral contacts. This cadherin-catenin complex anchors F-actin and bridges neighboring cells thereby reducing oral cancer cell motility.

\section{LCK is differentially expressed and a prognostic factor in HNSCC}

Since our integrative expression analyses in combination with functional in vitro cell line data suggested an important role of LCK in modulating oral cancer cell aggressiveness, we wanted to analyze the expression and prognostic relevance of LCK in more detail. To this end, we took advantage of the TCGA Head and Neck Squamous Cell Carcinoma (TCGA HNSC) dataset and the online analysis platform UALCAN [31]. Initial LCK expression analysis revealed a significantly higher LCK expression in tumors compared to normal tissues (Supplementary Fig. 7A). Importantly, LCK was consistently higher expressed across all tumor stages, grades and nodal status (Supplementary Fig. 7B-D) compared to normal tissue control. While there was no clear correlation between LCK expression and increasing tumor stages, the level of LCK increased with higher tumor grading (G1 vs. G2: $p=4.64 \mathrm{E}-03 ; \mathrm{G} 2$ vs. G3: $p=1.00 \mathrm{E}-$ $04 ; \mathrm{G} 3$ vs. G4: $p=0.055)$. There was also a trend towards higher LCK levels in tumors with more lymph node metastases (N1 vs. N3: $p=0.027$ ).

Next, we analyzed the association of LCK with overall (OS) and disease-free survival (DFS) using the GEPIA2 web server [32]. Analysis of the TCGA HNSCC dataset revealed that higher LCK expression significantly correlated with better OS, but not DFS (Fig. 7A, Supplementary Fig. 7E). Since our in vitro data suggested that LCK particularly correlates with the invasiveness / aggressiveness of more mesenchymal cells, i.e. $\mathrm{Vim}^{\text {high }} / \mathrm{N}$-cad ${ }^{\text {high }}$ (Fig. 3F, Supplementary Fig. 3B), we performed a more detailed survival analysis by considering different molecular subtypes of HNSCC. First, we noticed a higher expression of LCK in the atypical and mesenchymal subtypes compare to the basal and classical subtypes (Fig. 7B). Intriguingly, high LCK expression was specifically associated with worse DFS in the mesenchymal subtype only (Fig. 7C). Furthermore, we analyzed the OSCC subgroup of HNSCC and identified high LCK expression as a poor prognostic factor in tumors that expressed high levels of the mesenchymal marker $\mathrm{N}$-cadherin $\left(\mathrm{CDH} 2^{\text {high }}\right.$ ) (Fig. 7D). Taken together, these data imply a subtype-specific prognostic and potentially therapeutic relevance of LCK in human HNSCC.

Last but not least, we performed immunohistochemical analyses using four tissue samples from oral cancer patients in order to investigate LCK protein expression and localization within the primary tumor as well as in tumor-infiltrating lymphocytes (Fig. 7E). As expected, LCK was strongly expressed in lymphocytes (marked by black arrowheads). However, tumor cells also expressed LCK, albeit to a lesser extent. Most interestingly, tumor cells within the infiltration area (black arrows) showed a higher LCK expression compared to the rest of the primary tumor (asterisks). While these initial findings require further validation in a larger tissue collection, they are well in line with our functional cell line data and suggest that LCK expressing tumor cells could drive tumor invasion which could result in a more aggressive disease and a reduced disease-free survival of oral cancer patients.

\section{Discussion}

Intratumoral heterogeneity and phenotypic plasticity are commonly observed in human cancers and are critical for metastatic dissemination as well as therapy failure [55]. Here, we took advantage of this intrinsic variability to identify subpopulations of oral cancer cells that possess a highly invasive capacity. Subsequent integrative gene expression and molecular analyses revealed for the first time the important role of LCK, a member of the Src family of non-receptor tyrosine kinases, in oral cancer cell migration, invasion and metastasis due to its impact on cell-cell contact formation and differentiation. While our study focused on oral cancer and comprehensively investigated the function of LCK in an oral 


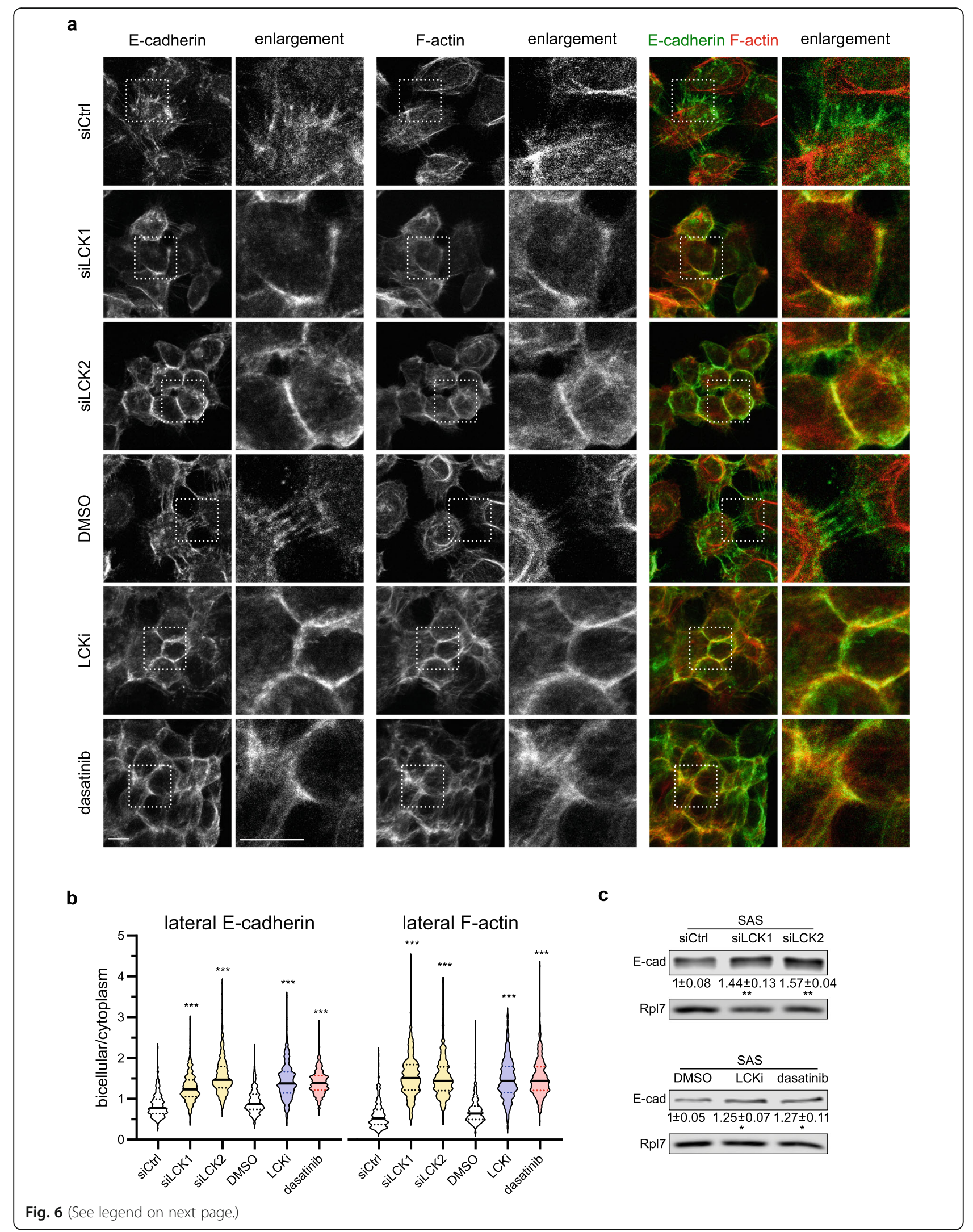


(See figure on previous page.)

Fig. 6 LCK inhibition promotes adherens junction formation. A SAS cells were transfected with non-targeting (siCtrl) or LCK-directed siRNAs (siLCK1, siLCK2) for $48 \mathrm{~h}$ or treated with DMSO, LCKi or dasatinib for $24 \mathrm{~h}$. Confocal images show E-cadherin and F-actin localization in treated compared to non-treated cells. Maximum intensity projections of at least 6 optical sections are depicted $(n=3$; scale bars $=10 \mu \mathrm{m})$. B Violin plots depict the enrichment factor of E-cadherin (left panel) and F-actin (right panel) at lateral contacts in SAS cells after knockdown or inhibition of LCK. About 500 individual bicellular contacts were measured. To determine statistical significances, one-way ANOVA was performed. C Western blot of protein lysates after $48 \mathrm{~h}$ of LCK knockdown or $24 \mathrm{~h}$ of LCK inhibitor treatment to analyze E-cadherin protein abundance. Rpl7 was used for loading control. $\left({ }^{*} p<0.05,{ }^{* *} p<0.01,{ }^{* * *} p<0.001\right)$

squamous cell carcinoma-derived cell line, it is important to note that LCK has previously been shown to be aberrantly expressed in colon, prostate, and small cell lung carcinoma cells with a trend towards preferential expression in metastatic cancers [56, 57]. In this context it is worth mentioning that LCK primarily functions in lymphocytes where it is involved in signal transduction from the $\mathrm{T}$ cell receptor complex to the nucleus [58]. This immune cell-specific expression and function might partially explain the seemingly contradictory connection between high LCK expression and improved HNSCC patient survival (Fig. 7A). Similar findings have been described recently in human breast cancer. Van Roosmalen et al. performed an unbiased siRNA screen and identified LCK as an important factor supporting breast cancer cell motility. However, high expression of LCK in estrogen-receptor positive and negative breast cancer samples was associated with a better metastasis-free survival [49]. Nevertheless, our detailed survival analyses (Fig. 7B-C) suggest that LCK might preferentially affect the aggressiveness and outcome of mesenchymal HNSC $\mathrm{C}$, which needs to be confirmed and functionally tested in the future. The biological role of LCK in cancer cell motility, as described herein, supports the concept of lymphocyte mimicry, a cellular differentiation program which enables a transformed epithelium to adopt a behavior normally restricted to lymphocytes, including anchorage-independent mobilization, thereby gaining metastatic properties as it has been shown, e.g., in lung cancer cells overexpressing the lineage-specific transcription factor Aiolos [59]. However, the cellular and molecular functions of LCK in cancer metastasis and cell motility are not fully understood yet. Recently, a promigratory effect of LCK was observed in glioblastoma, which has been linked to an increased phosphorylation of Paxillin on tyrosine 118 [50], an important posttranslational modification associated with migration and focal adhesion turnover [60]. While we did not observe changes in phospho-Y118 levels, we noted a significant accumulation of total Paxillin protein upon LCK inhibition in SAS cells thereby decreasing the relative amount of Y118-phosphorylated Paxillin (Fig. 4G, H), which could lead to an altered focal adhesion formation and affect the actin cytoskeleton. Indeed, knockdown or inhibition of LCK was accompanied by a reorganization of the actin cytoskeleton resulting in cortical F-actin localization as well as an extensive co-localization of Ecadherin and F-actin at lateral membranes (Fig. 6A). Importantly, LCK inhibition strongly enhanced the formation of AJs as indicated by the accumulation of Ecadherin, $\beta$-catenin, p120-catenin and Plakophilin 4 at lateral contacts. These positional changes increased the epithelial characteristics of the cells and reduced their invasive and migratory properties. This was also reflected on the transcriptional level, as LCK inhibition triggered a cellular differentiation program by increasing the abundance of TGM1, KRT14, KRT17 and other genes that have been linked to cornification, an important differentiation process of oral epithelial cells [61, 62]. Hence, inhibition of LCK in oral cancer cells has the potential to modulate cancer cell plasticity by inducing differentiation to a less malignant state [63].

To achieve effective inhibition in our study we took advantage of two small molecule inhibitors, which we applied in sub-lethal doses to inhibit oral cancer cell motility. While the LCK inhibitor A-770041 showed in vitro activity comparable to the pan-Src family kinase inhibitor dasatinib, the latter has a higher potency and is already clinically approved for the treatment of CML and ALL. Importantly, dasatinib as well as another panSrc family inhibitor called saracatinib proved their ability to decrease tumor growth and metastasis formation in several pre-clinical studies across multiple cancer entities [64-70]. However, many clinical trials testing these compounds in the metastatic setting in diverse solid tumor entities were discontinued or failed [71-85]. In patients with recurrent or metastatic HNSCC, single agent phase II trials of saracatinib [86] as well as dasatinib failed [87]. However, a phase II trial in biomarkerunselected patients with cetuximab-resistant recurrent or metastatic HNSCC revealed a specific clinical benefit of dasatinib addition and improved overall survival only among patients with low serum levels of interleukin 6 (IL6) [88]. Since we and others identified LCK as an important regulator of cancer cell motility, it would be interesting to investigate, if patient stratification based on intratumoral LCK expression could identify additional patient populations that would benefit from single agent or combination therapy. Following this idea, we performed a preliminary analysis in which we correlated 
a

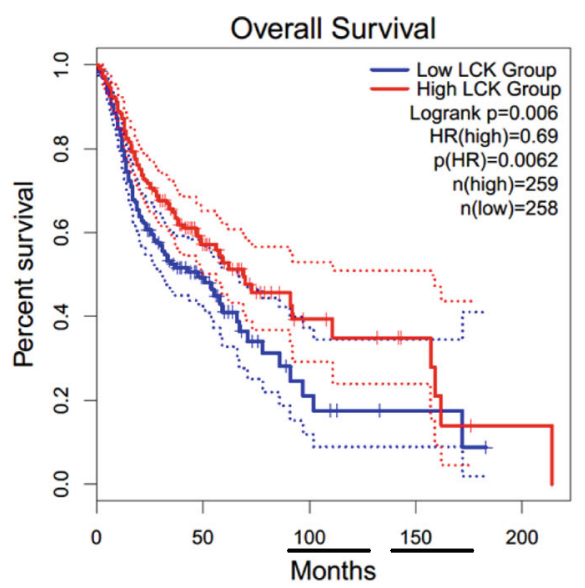

C

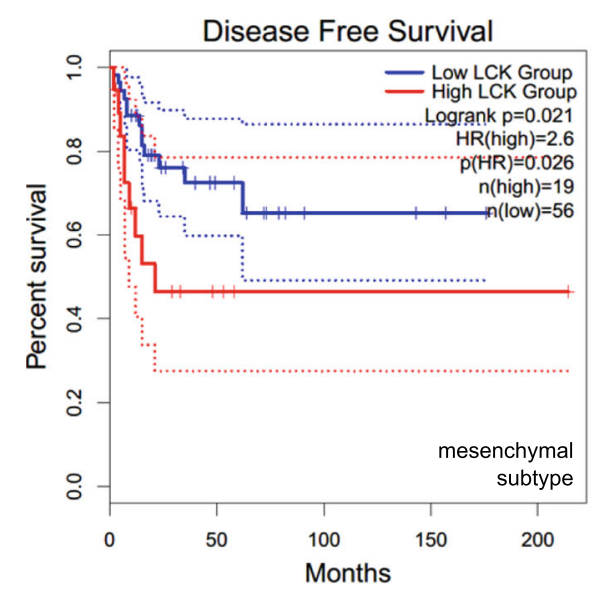

e

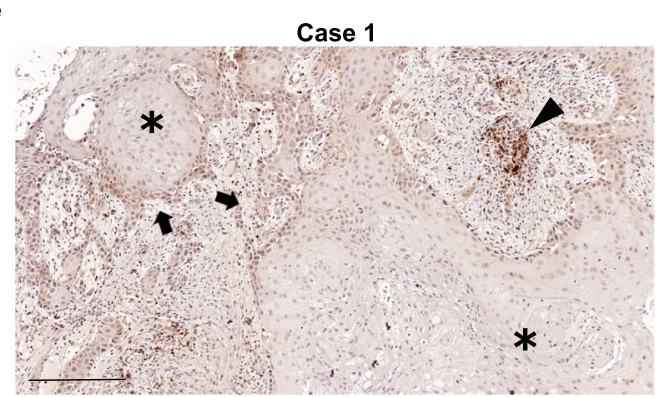

Case 3

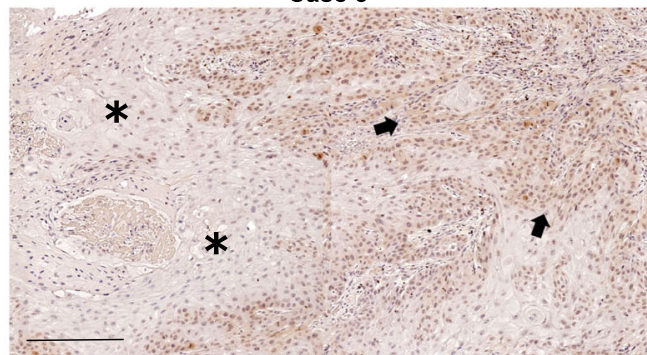

b

d
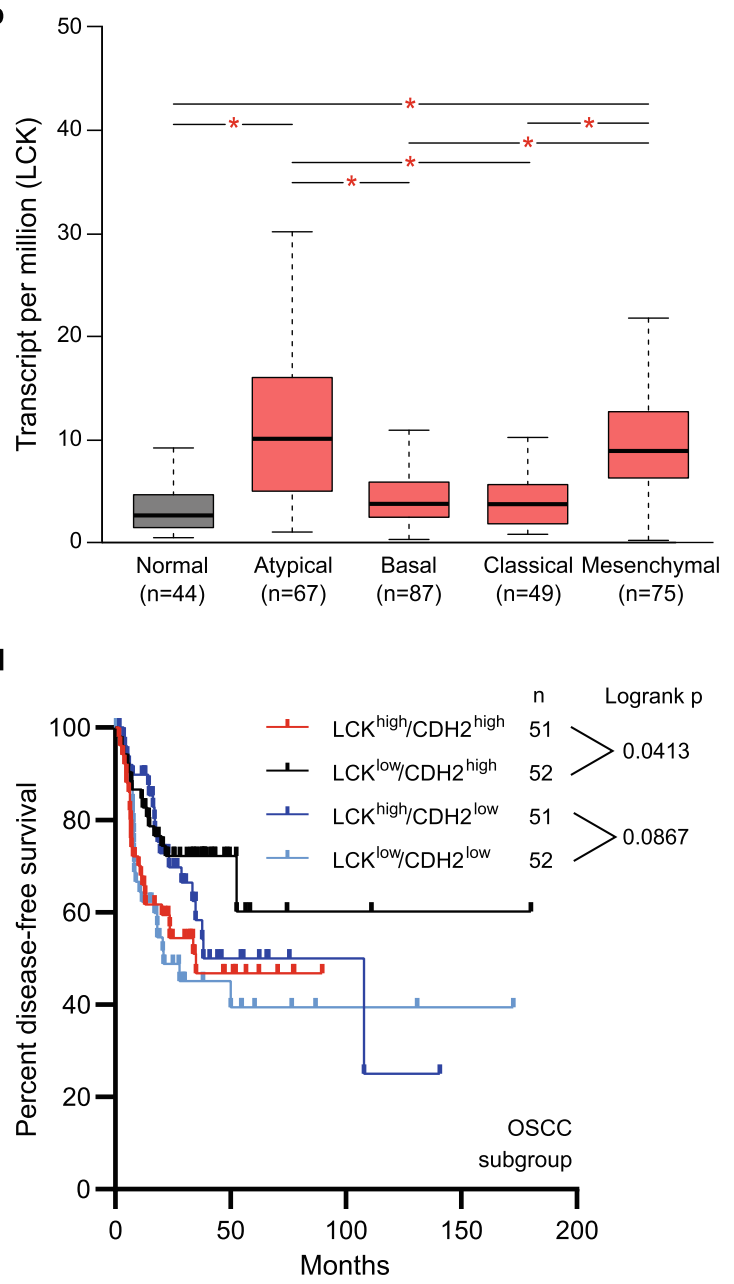

Case 2

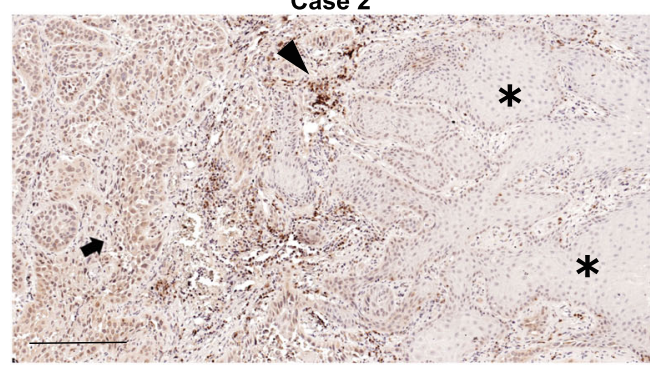

Case 4

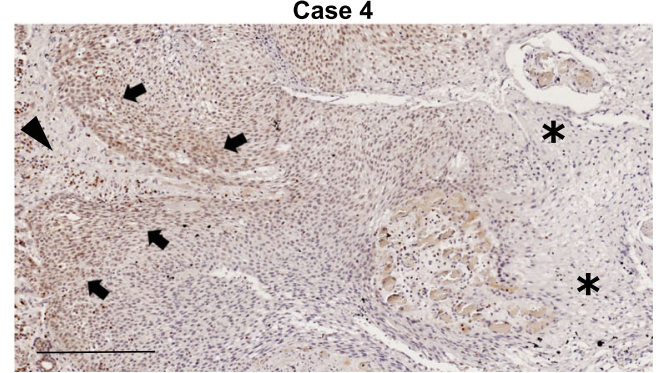

Fig. 7 (See legend on next page.) 
(See figure on previous page.)

Fig. 7 Prognostic relevance of LCK in HNSCC. Survival analyses were performed using the online tool GEPIA2 (http://gepia2.cancer-pku.cn/). A High LCK expression was associated with better overall survival in the TCGA HNSCC dataset. B Differential expression of LCK across individual molecular subtypes of HNSCC. C Kaplan-Meier analysis of disease-free survival in the mesenchymal subtype of HNSCC stratified by LCK mRNA abundance. D Kaplan-Meier curves for disease-free survival of OSCC patients only within the TCGA HNSCC dataset. The OSCC subgroup was first split at the median of $\mathrm{CDH} 2$ (CDH2 ${ }^{\text {high }}$ vs. $\left.\mathrm{CDH} 2^{\text {low }}\right)$. In all groups, DFS of patients with LCK ${ }^{\text {high }}$ and LCK ${ }^{\text {low }}$ tumors (median split) was compared. $\mathbf{E}$ Immunohistochemical analysis of LCK in four cases of oral cancer. Strong LCK expression was found in lymphocytes (black arrowheads). Tumor cells within the infiltration area (black arrows) show a higher LCK expression compared to the rest of the primary tumor (asterisks). Scale bars, $250 \mu \mathrm{m}$

LCK and SRC mRNA expression in about 500 human cancer cell lines with the metastatic potential of the respective cells (Supplementary Fig. 8A-G). This analysis revealed that neither LCK nor SRC transcript levels correlated with the metastatic potential across 488 cell lines. However, LCK (but not SRC) expression in 21 cancer cell lines of the upper aerodigestive tract correlated with the general metastatic potential, i.e. metastasis to all five investigated organs $(\mathrm{r}=0.467, p=0.0328)$, especially with metastasis to the bone $(\mathrm{r}=0.474, p=0.0297)$ and $\mathrm{a}$ trend is seen for lung metastasis $(r=0.366, p=0.1024)$ as well. In contrast, SRC (but not LCK) transcript abundance was strongly correlated with liver metastasis of these 21 cell lines $(r=0.698, p=0.0004)$. These preliminary findings further imply a critical role of LCK in cancer metastasis and suggest a "division of labor" among both tyrosine kinases, whose differential activities or expression patterns might contribute to the observed organotropism of HNSCC-derived cancer cells. Consequently, shifting the focus away from Src might help to better understand the therapeutic potential of pan-Src family kinase inhibitors like dasatinib and could lead to the development of more specific inhibitors with reduced side-effects. In line with this, immunotherapybased approaches that would more directly target LCK overexpressing cancer cells, instead of broadly inhibiting Src family kinases through small molecules, might be an interesting alternative. In fact, earlier studies could demonstrate that the $L C K$ gene encodes antigenic epitopes recognized by HLA class I-restricted and tumor-specific cytotoxic T lymphocytes (CTLs) of metastatic cancer patients. In detail, LCK-derived peptides increased CTL activity in peripheral blood mononuclear cells (PBMC) of colon and other epithelial cancer patients with distant metastases, but not those without distant metastases. Thus, LCK peptides, especially those derived from the C-terminal region (LCK486-494 (TFDYLRSVL) and LCK488-497 (DYLRSVLEDF), could be useful in developing a specific immunotherapy for cancer patients with distant metastases $[56,89]$. Based on these initial findings a monoclonal antibody (mAb) recognizing the LCK486-494 peptide was recently developed. The mAb showed antitumor activity in immunocompetent Balb/c mice challenged with murine Colon-26 cells and an even more potent tumor inhibition was observed when this mAb was given prior to a LCK peptide vaccination [90]. This study suggests that therapeutic strategies directed against LCK might not only show effects on tumor metastasis, but could also inhibit tumor growth.

\section{Conclusion}

In summary, we show that clonal heterogeneity of established cancer cell lines can be exploited to identify important driver genes contributing to clinical relevant cancer cell phenotypes. Moreover, our study unraveled the cellular and molecular mechanisms of LCK inhibition in human oral squamous cancer cells using genetic and chemical targeting strategies. Future studies should evaluate LCK as a potential biomarker for patient stratification as well as investigate its targeting potential for anti-metastasis therapy. While our study provides strong in vitro evidence for a function of LCK in oral cancer cell migration and invasion, additional in vivo experiments are necessary to establish LCK as a relevant and druggable target to prevent cancer metastasis. Moreover, phosphoproteomics as well as protein interaction studies should be performed to identify key substrates of LCK, which will enable a deeper mechanistic understanding of the signaling pathways involved in LCK-dependent differentiation and invasion of oral cancer cells. These analyses are important in order to develop cancer-specific LCK inhibitors that do not interfere with immune cell functions by blocking LCK signaling in lymphocytes.

\section{Abbreviations}

AJ: adherens junction; ALL: Acute lymphoblastic leukemia; $C D H$ : Cadherin; CDKN2A: Cyclin dependent kinase inhibitor 2A; cDNA: complementary DNA; CML: Chronic myeloid leukemia; CTSV: Cathepsin V; DFS: disease-free survival; DMSO: Dimethyl sulfoxide; ECM: Extracellular matrix; EGFR: Epithelial growth factor receptor; EMT: Epithelial-to-mesenchymal-transition; ETV4: ETS variant transcription factor 4; FACS: Fluorescence-activated cell sorting; FBS: fetal bolvine serum; FDA: U.S. Food and drug administration; FDR: false discovery rate; FN1: Fibronectin 1; HNSCC: Head and neck squamous cell carcinoma; HPV: Human papilloma virus; IL: Interleukin; ITGB: Integrin subunit $\beta$; ITH: intra-tumoral heterogeneity; IVL: Involucrin; JAK: Janus kinase; KRT: Keratin; KIF21B: Kinesin Family Member 21B; LAPTM5: Lysosomal protein transmembrane 5; LCK: Lymphocyte cell-specific protein-tyrosine kinase; $\log 2(C P M)$ : binary logarithm of counts per million; LPXN: Leupaxin; mAB: monoclonal antibody; MAPK: Mitogen-activated protein kinase; MMLV: Moloney murine leukemia virus.; MMP: Matrix metallopeptidase.; mRNA: messenger RNA.; mTOR: mammalian target of rapamycin.; NK: Natural killer.; OLR1: Oxidized low density lipoprotein receptor 1.; OS: overall survival.; OSCC: Oral squamous cell carcinoma.; PAI-2: plasminogen activator inhibitor 
type-2.; PI3K: Phosphatidylinositol-3-kinase.; POLR2A: RNA Polymerase II Subunit A.; PPIA: Peptidylprolyl isomerase A.; RT-qPCR: Reverse Transcriptase quantitative polymerase chain reaction.; RB1: Retinoblastoma-associated protein 1.; RBL1/2: RB transcriptional corepressor like 1.; Rpl7: Ribosomal Protein L7.; RPLPO: Ribosomal Protein Lateral Stalk Subunit PO.; RT: room temperature.; SERPINB2: Serpin Family B Member 2.; siRNA: small interfering RNA.; SPRR: Small Proline-rich.; STAT: Signal transducer and activator of transcription.; TCGA: The cancer genome atlas.; TGM1: Transglutaminase 1.; TKI: Tyrosine kinase inhibitor.; TP53: Tumor protein P53.; VIM: Vimentin.

\section{Supplementary Information}

The online version contains supplementary material available at https://doi. org/10.1186/s12943-021-01384-w.

Additional file 1 Supplementary Fig. 1. Expression of invasion and EMT-associated genes in HNSCC-derived cell lines. A, B RT-qPCR was used to detect indicated genes. RPLPO and PPIA served as reference genes. Expression values were normalized against the average expression across all cell lines. Significance test was performed with student's t-test comparing one cell line with the other three $\left(n=3 ;{ }^{*} p<0.05,{ }^{* *} p<0.01\right.$, ${ }^{* * *} p<0.001$ ). C Representative Western blot showing the expression of the epithelial marker E-cadherin and the mesenchymal markers $\mathrm{N}$ cadherin and Vimentin. Rpl7 was used to control for equal protein loading.

Additional file $\mathbf{2}$ Supplementary Fig. 2. Mesenchymal characteristics and invasiveness of SAS subclones. A Correlation of the Vimentin/Ecadherin and $\mathrm{N}$-cadherin/E-cadherin protein expression ratio to the relative invasiveness of each SAS subclone. B $\mathrm{N}$-cadherin protein abundance was plotted against Vimentin abundance, whereby SAS subclones divide in two groups: Vim high $/ \mathrm{N}$-cad ${ }^{\text {high }}$ (red) or Vim ${ }^{\text {low }} / \mathrm{N}$-cad ${ }^{\text {low }}$ (blue).

Additional file 3 Supplementary Fig. 3. Correlation between LCK protein expression and clonal invasiveness. A Western blot of LCK in 20 SAS subclones and the parental SAS cell line. Rpl7 served as loading control. B The protein abundance of LCK was plotted against the invasion factor and separately against the relative invasion area and invasion start time. Correlation analysis was performed considering the grouping in Vim high/N-cad high (red) or Vim ${ }^{\text {low }} / \mathrm{N}$-cad ${ }^{\text {low }}$ (blue) subclones. Depicted in black: correlation across all 20 clones (no subgrouping).

Additional file 4 Supplementary Fig. 4. Migration of HNSCC cell lines after LCK inhibition. A-C 2D migration analysis upon LCKi (500 nM) or dasatinib $(100 \mathrm{nM})$ treatment directly after the scratch was performed in the HNSCC cell line panel. Representative pictures of the scratch wound assay were taken 12 and $24 \mathrm{~h}$ after the scratch (scale bar $=400 \mu \mathrm{m}$ ). The initial scratch wound is labeled in purple and the cell layer in orange. D The normalized slope of a linear regression of the wound density over time is plotted $(n=3)$. E Representative Western blot showing Paxillin and Y118 phosphorylated Paxillin abundance in HNSCC-derived cells. Same Rpl7 loading control as shown in Suppl. Fig. 1C (i.e. same membrane used for detection). F Total and $\mathrm{p}(\mathrm{Y} 118)$-Paxillin levels in weak ( $F \& L$ ) and strong ( $H \& S$ ) invasive SAS subclones using Rpl7 as loading control. Relative phosphorylation state was normalized to the average of all four cell lines or clones, respectively. Statistical significance was calculated via Student's t-test $\left(n=3 ;{ }^{*} p<0.05,{ }^{* *} p<0.01,{ }^{* * *} p<0.001\right)$.

Additional file $\mathbf{5}$ Supplementary Fig. $\mathbf{5}$. LCK-dependent gene expression. A Expression correlation analysis of LCK and LCK-associated genes in the TCGA HNSCC dataset derived from gepia2.cancer-pku.cn. The Pearson correlation coefficient (R) and $p$-values are given. B Confirmation of differential gene expressions after LCK inhibition and knockdown using RT-qPCR analysis for selected genes. C RT-qPCR analysis to detect Ecadherin and $\beta$-catenin mRNAs after $48 \mathrm{~h} \mathrm{LCK} \mathrm{knockdown} \mathrm{and} 24 \mathrm{~h} \mathrm{LCK}$ inhibition. In $\mathbf{B}$ and $\mathbf{C}$, PPIA and RPLPO were used as reference genes and samples normalized to siCtrl and DMSO $\left({ }^{*} p<0.05,{ }^{* *} p<0.01,{ }^{* * *} p<\right.$ $0.001)$

Additional file 6 Supplementary Fig. 6. Localization of $\beta$-catenin, p120 and Plakophilin 4 after LCK inhibition. A SAS cells were transfected with non-targeting (siCtrl) or LCK-directed siRNAs (siLCK1, siLCK2) for $48 \mathrm{~h}$ or treated with DMSO, LCKi or dasatinib for $24 \mathrm{~h}$, fixed in methanol for $10 \mathrm{~min}$ at $-20^{\circ} \mathrm{C}$, and immunostained for $\beta$-catenin, p120-catenin and
Plakophilin4. Confocal images show $\beta$-catenin (left panel), p120-catenin (middle panel) and Plakophilin4 (right panel) localizations. Maximum intensity projections of at least 7 optical sections are depicted (scale bars $=$ $20 \mu \mathrm{m}$ ). B Violin plots depict the enrichment factor of $\beta$-catenin (left panel), p120-catenin (middle panel) and Plakophilin 4 (right panel) at lateral contacts after knockdown or inhibition of LCK. About 500 individual contacts were measured. To determine statistical significances one-way ANOVA was performed (***p $<0.001)$.

Additional file 7 Supplementary Fig. 7. Expression of LCK in the TCGA HNSCC dataset. A Higher LCK transcript abundance in primary tumors compared to normal tissue. B Expression of LCK across tumor stages. C Expression of LCK across tumor grades. D Expression of LCK across tumors with different nodal status. Data obtained and modified from UALCAN (http://ualcan.path.uab.edu/). E Kaplan-Meier survival curve for disease-free survival of TCGA HNSCC patients stratified by LCK transcript expression levels (GEPIA2).

Additional file 8 Supplementary Fig. 8. Correlation between LCK or SRC transcript abundance and the metastasis potential of human cancer cell lines. Based on the 'metastasis map of human cancer cell lines' of the Broad Institute (https://depmap.org/metmap/), SRC and LCK mRNA level in $\sim 500$ cell lines of multiple origins (all) and 21 cell lines originating from the upper aerodigestive tract (HNSCC) were correlated with their respective general metastatic potential across all sites (brain, lung, liver, kidney, bone) or their site-specific potential. A Magnitude of correlation (Pearson correlation coefficient) between LCK (yellow bars) and SRC (blue bars) expression and the metastatic potential of $\sim 500$ cells (triangle) or 21 upper aerodigestive tract cancer cells (circle) across all five sites or each site individually. The significance value $p$ of the slope being nonzero of a correlation analysis is labelled $\left({ }^{*} p<0.05,{ }^{* *} p<0.01,{ }^{* * *} p<\right.$ 0.001). B-G Plots of LCK (yellow) or SRC (blue) mRNA level in the 21 upper aerodigestive tract cancer cell lines against their respective metastasis potential to different organ site.

\section{Acknowledgments}

The authors would like to thank all members of the Gutschner \& Hämmerle labs for helpful discussions, the Core Facility Imaging (CFI) and Dr. Nadine Bley for help with IncuCyte measurements, and the online platform usegalaxy.eu for sharing analysis tools. Moreover, we thank the Broad Institute for providing access to RNA expression data of the CCLE (https:// portals.broadinstitute.org/ccle). We declare that those who carried out the original analysis and collection of the Data bear no responsibility for the further analysis or interpretation of it. We also thank Xin Jin and colleagues for making the metastasis map publically available (https://depmap.org/ metmap/). In addition, some of the results shown here are in whole or part based upon data generated by the TCGA Research Network: https://www. cancer.gov/tcga.

\section{Authors' contributions}

The study was conceptualized by J.W. and T.G. with input from M. Haemmerle, W.G.B., M. Hatzfeld. Experiments were performed by J.W., J.R., and L.M. Patient tumor samples were collected by M.K. and A.W.E. Bioinformatical analysis was performed by J.W., M.G., D.M. and S.H. Analysis of data was done by J.W., J.R., L.M., M. Hatzfeld, M. Haemmerle and T.G. The manuscript was written by J.W., L.M., M. Hatzfeld, M. Haemmerle and T.G. Figures were prepared by J.W. and L.M. All authors have read and agreed to the final version of the manuscript. The author(s) read and approved the final manuscript.

\section{Funding}

This study was supported by intramural funding from the Medical Faculty (Wilhelm-Roux program) to T.G. In addition, we acknowledge the financial support of the Open Access Publication Fund of the Martin-Luther-University Halle-Wittenberg.

\section{Availability of data and materials}

The datasets used and/or analyzed during the current study are available from the corresponding author on reasonable request. 


\section{Declarations}

\section{Ethics approval and consent to participate}

Ethical registry 210/19.08.09/10 was obtained from the Ethics Committee of the Medical Faculty of the University Halle. All patients gave written informed consent (Department of Oral and Maxillofacial Plastic Surgery, University of Halle-Wittenberg, Germany).

\section{Consent for publication}

Not applicable.

\section{Competing interests}

The authors declare that they have no competing interests.

\section{Author details}

'Junior Research Group 'RNA biology and pathogenesis', Faculty of Medicine, Martin Luther University Halle-Wittenberg, 06120 Halle, Germany. ${ }^{2}$ Institute of Molecular Medicine, Section for Pathobiochemistry, Faculty of Medicine, Martin Luther University Halle-Wittenberg, 06120 Halle, Germany. ${ }^{3}$ Department of Oral and Maxillofacial Plastic Surgery, Faculty of Medicine, Martin Luther University Halle-Wittenberg, 06120 Halle, Germany. ${ }^{4}$ Department of Cranio Maxillofacial Surgery, Paracelsus Medical University, 90471 Nuremberg, Germany. ${ }^{5}$ Institute of Molecular Medicine, Section for Molecular Cell Biology, Faculty of Medicine, Martin Luther University Halle-Wittenberg, 06120 Halle, Germany. ${ }^{6}$ Institute of Molecular Medicine, Section for Molecular Oncology, Faculty of Medicine, Martin Luther University Halle-Wittenberg, 06120 Halle, Germany. 'Institute of Pathology, Section for Experimental Pathology, Medical Faculty, Martin Luther University Halle-Wittenberg, 06112 Halle, Germany.

\section{Received: 22 November 2020 Accepted: 31 May 2021}

\section{Published online: 11 June 2021}

\section{References}

1. Bray F, Ferlay J, Soerjomataram I, Siegel RL, Torre LA, Jemal A. Global cancer statistics 2018: GLOBOCAN estimates of incidence and mortality worldwide for 36 cancers in 185 countries. CA Cancer J Clin. 2018;68(6):394-424. https://doi.org/10.3322/caac.21492.

2. Miranda-Filho A, Bray F. Global patterns and trends in cancers of the lip, tongue and mouth. Oral Oncol. 2020;102:104551. https://doi.org/10.1016/j. oraloncology.2019.104551.

3. Groeger S, Meyle J. Oral mucosal epithelial cells. Front Immunol. 2019;10: 208. https://doi.org/10.3389/fimmu.2019.00208

4. Tang XH, Scognamiglio T, Gudas LJ. Basal stem cells contribute to squamous cell carcinomas in the oral cavity. Carcinogenesis. 2013;34(5): 1158-64. https://doi.org/10.1093/carcin/bgt021.

5. Vig N, Mackenzie IC, Biddle A. Phenotypic plasticity and epithelial-tomesenchymal transition in the behaviour and therapeutic response of oral squamous cell carcinoma. J Oral Pathol Med. 2015;44(9):649-55. https://doi. org/10.1111/jop.12306

6. de Camargo Cancela M, de Souza DL, Curado MP. International incidence of oropharyngeal cancer: a population-based study. Oral Oncol. 2012;48(6):48490. https://doi.org/10.1016/j.oraloncology.2011.12.013.

7. Graham S, Dayal H, Rohrer T, Swanson M, Sultz H, Shedd D, et al. Dentition, diet, tobacco, and alcohol in the epidemiology of oral cancer. J Natl Cancer Inst. 1977;59(6):1611-8. https://doi.org/10.1093/jnci/59.6.1611.

8. Muttagi SS, Gaikwad R, Pawar P, Chaturvedi P, Singh B. Head and neck squamous cell carcinoma in chronic areca nut chewing Indian women: case series and review of literature. Indian J Med Paediatr Oncol. 2012;33(1):32-5. https://doi.org/10.4103/0971-5851.96966.

9. Alsahafi E, Begg K, Amelio I, Raulf N, Lucarelli P, Sauter T, et al. Clinical update on head and neck cancer: molecular biology and ongoing challenges. Cell Death Dis. 2019;10(8):540. https://doi.org/10.1038/s41419-01 9-1769-9.

10. Kang $\mathrm{H}$, Kiess $\mathrm{A}$, Chung $\mathrm{CH}$. Emerging biomarkers in head and neck cancer in the era of genomics. Nat Rev Clin Oncol. 2015;12(1):11-26. https://doi. org/10.1038/nrclinonc.2014.192.

11. Sessions DG, Spector GJ, Lenox J, Parriott S, Haughey B, Chao C, et al. Analysis of treatment results for floor-of-mouth cancer. Laryngoscope. 2000; 110(10 Pt 1):1764-72. https://doi.org/10.1097/00005537-200010000-00038.
12. Sim YC, Hwang JH, Ahn KM. Overall and disease-specific survival outcomes following primary surgery for oral squamous cell carcinoma: analysis of consecutive 67 patients. J Korean Assoc Oral Maxillofac Surg. 2019;45(2):8390. https://doi.org/10.5125/jkaoms.2019.45.2.83.

13. Duprez F, Berwouts D, de Neve W, Bonte K, Boterberg T, Deron P, et al. Distant metastases in head and neck cancer. Head Neck. 2017;39(9):173343. https://doi.org/10.1002/hed.24687.

14. Valastyan S, Weinberg RA. Tumor metastasis: molecular insights and evolving paradigms. Cell. 2011;147(2):275-92. https://doi.org/10.1016/j.cell.2 011.09.024.

15. LaFave LM, Kartha VK, Ma S, Meli K, del Priore I, Lareau C, et al. Epigenomic state transitions characterize tumor progression in mouse lung adenocarcinoma. Cancer Cell. 2020;38(2):212-28 e13. https://doi.org/10.101 6/j.ccell.2020.06.006.

16. Marjanovic ND, Hofree M, Chan JE, Canner D, Wu K, Trakala M, et al. Emergence of a high-plasticity cell state during lung Cancer evolution. Cancer Cell. 2020;38(2):229-46 e13. https://doi.org/10.1016/j.ccell.2020.06. 012.

17. Welch DR, Hurst DR. Defining the hallmarks of metastasis. Cancer Res. 2019; 79(12):3011-27. https://doi.org/10.1158/0008-5472.CAN-19-0458.

18. Jayanthi $P$, Varun BR, Selvaraj J. Epithelial-mesenchymal transition in oral squamous cell carcinoma: an insight into molecular mechanisms and clinical implications. J Oral Maxillofac Pathol. 2020;24(1):189. https://doi.org/1 0.4103/jomfp.JOMFP_334_19.

19. Lu W, Kang Y. Epithelial-mesenchymal plasticity in Cancer progression and metastasis. Dev Cell. 2019;49(3):361-74. https://doi.org/10.1016/j.devcel.2019.04.010.

20. Campbell K, Casanova J. A common framework for EMT and collective cell migration. Development. 2016;143(23):4291-300. https://doi.org/10.1242/ dev.139071.

21. Williams ED, Gao D, Redfern A, Thompson EW. Controversies around epithelial-mesenchymal plasticity in cancer metastasis. Nat Rev Cancer. 2019:19(12):716-32. https://doi.org/10.1038/s41568-019-0213-x.

22. Greaves M. Evolutionary determinants of cancer. Cancer Discov. 2015;5(8): 806-20. https://doi.org/10.1158/2159-8290.CD-15-0439.

23. Gissi DB, Tarsitano A, Leonardi E, Gabusi A, Neri F, Marchetti C, et al. Clonal analysis as a prognostic factor in multiple oral squamous cell carcinoma. Oral Oncol. 2017;67:131-7. https://doi.org/10.1016/j.oraloncology.2017.02.017.

24. Morandi L, Tarsitano A, Gissi D, Leonardi E, Balbi T, Marchetti C, et al. Clonality analysis in primary oral squamous cell carcinoma and related lymph-node metastasis revealed by TP53 and mitochondrial DNA next generation sequencing analysis. J Craniomaxillofac Surg. 2015;43(2):208-13. https://doi.org/10.1016/j.jcms.2014.11.007.

25. Ha PK, Chang SS, Glazer CA, Califano JA, Sidransky D. Molecular techniques and genetic alterations in head and neck cancer. Oral Oncol. 2009:45(4-5): 335-9. https://doi.org/10.1016/j.oraloncology.2008.05.015.

26. Chomczynski P, Sacchi N. Single-step method of RNA isolation by acid guanidinium thiocyanate-phenol-chloroform extraction. Anal Biochem. 1987; 162(1):156-9. https://doi.org/10.1016/0003-2697(87)90021-2.

27. Schindelin J, Arganda-Carreras I, Frise E, Kaynig V, Longair M, Pietzsch T, et al. Fiji: an open-source platform for biological-image analysis. Nat Methods. 2012;9(7):676-82. https://doi.org/10.1038/nmeth.2019.

28. Müller $L$, et al. Plakophilin 3 phosphorylation by ribosomal $S 6$ kinases supports desmosome assembly. J Cell Sci. 2020;133(8):jcs238295. https://doi. org/10.1242/jcs.238295.

29. Ghandi M, Huang FW, Jané-Valbuena J, Kryukov GV, Lo CC, McDonald ER III, et al. Next-generation characterization of the Cancer cell line encyclopedia. Nature. 2019;569(7757):503-8. https://doi.org/10.1038/s41586-019-1186-3.

30. Jin X, Demere Z, Nair K, Ali A, Ferraro GB, Natoli T, et al. A metastasis map of human cancer cell lines. Nature. 2020;588(7837):331-6. https://doi.org/10.103 8/s41586-020-2969-2.

31. Chandrashekar DS, Bashel B, Balasubramanya SAH, Creighton CJ, PonceRodriguez I, Chakravarthi BVSK, et al. UALCAN: a portal for facilitating tumor subgroup gene expression and survival analyses. Neoplasia. 2017;19(8):649_ 58. https://doi.org/10.1016/j.neo.2017.05.002.

32. Tang Z, Kang B, Li C, Chen T, Zhang Z. GEPIA2: an enhanced web server for large-scale expression profiling and interactive analysis. Nucleic Acids Res. 2019;47(W1):W556-60. https://doi.org/10.1093/nar/gkz430.

33. Cerami E, Gao J, Dogrusoz U, Gross BE, Sumer SO, Aksoy BA, et al. The cBio cancer genomics portal: an open platform for exploring multidimensional cancer genomics data. Cancer Discov. 2012;2(5):401-4. https://doi.org/10.11 58/2159-8290.CD-12-0095. 
34. Gao J, et al. Integrative analysis of complex cancer genomics and clinical profiles using the cBioPortal. Sci Signal. 2013;6(269):pl1.

35. Grossman RL, Heath AP, Ferretti V, Varmus HE, Lowy DR, Kibbe WA, et al. Toward a shared vision for Cancer genomic data. N Engl J Med. 2016; 375(12):1109-12. https://doi.org/10.1056/NEJMp1607591.

36. Chien MH, Lin CW, Cheng CW, Wen YC, Yang SF. Matrix metalloproteinase-2 as a target for head and neck cancer therapy. Expert Opin Ther Targets. 2013;17(2):203-16. https://doi.org/10.1517/14728222.2013.740012.

37. Sokeland $\mathrm{G}$, Schumacher $\mathrm{U}$. The functional role of integrins during intraand extravasation within the metastatic cascade. Mol Cancer. 2019;18(1):12. https://doi.org/10.1186/s12943-018-0937-3.

38. Loh CY, et al. The E-Cadherin and N-Cadherin Switch in Epithelial-toMesenchymal Transition: Signaling, Therapeutic Implications, and Challenges. Cells. 2019;8(10):1118. https://doi.org/10.3390/cells8101118.

39. Okumura K, Konishi A, Tanaka M, Kanazawa M, Kogawa K, Niitsu Y Establishment of high- and low-invasion clones derived for a human tongue squamous-cell carcinoma cell line SAS. J Cancer Res Clin Oncol. 1996;122(4):243-8. https://doi.org/10.1007/BF01209653.

40. Adra CN, Zhu S, Ko JL, Guillemot JC, Cuervo AM, Kobayashi H, et al. LAPT M5: a novel lysosomal-associated multispanning membrane protein preferentially expressed in hematopoietic cells. Genomics. 1996;35(2):32837. https://doi.org/10.1006/geno.1996.0364.

41. Chen L, Wang G, Luo Y, Wang Y, Xie C, Jiang W, et al. Downregulation of LAPTM5 suppresses cell proliferation and viability inducing cell cycle arrest at G0/G1 phase of bladder cancer cells. Int J Oncol. 2017;50(1):263-71. https://doi.org/10.3892/ijo.2016.3788.

42. Berberich A, Bartels F, Tang Z, Knoll M, Pusch S, Hucke N, et al. LAPTM5CD40 crosstalk in glioblastoma invasion and Temozolomide resistance. Front Oncol. 2020;10:747. https://doi.org/10.3389/fonc.2020.00747.

43. Jin T, Kim HS, Choi SK, Hwang EH, Woo J, Ryu HS, et al. microRNA-200c/141 upregulates SerpinB2 to promote breast cancer cell metastasis and reduce patient survival. Oncotarget. 2017;8(20):32769-82. https://doi.org/10.18632/ oncotarget.15680.

44. Schroder WA, Major LD, le TT, Gardner J, Sweet MJ, Janciauskiene S, et al. Tumor cell-expressed SerpinB2 is present on microparticles and inhibits metastasis. Cancer Med. 2014;3(3):500-13. https://doi.org/10.1002/cam4.229.

45. Zhang XM, Wang T, Hu P, Li B, Liu H, Cheng YF. SERPINB2 overexpression inhibited cell proliferation, invasion and migration, led to G2/M arrest, and increased radiosensitivity in nasopharyngeal carcinoma cells. J Radiat Res. 2019;60(3):318-27. https://doi.org/10.1093/jrr/rrz003.

46. Bommhardt U, Schraven B, Simeoni L. Beyond TCR Signaling: Emerging Functions of Lck in Cancer and Immunotherapy. Int J Mol Sci. 2019;20(14): 3500. https://doi.org/10.3390/ijms20143500.

47. Mahabeleshwar GH, Das R, Kundu GC. Tyrosine kinase, p56lck-induced cell motility, and urokinase-type plasminogen activator secretion involve activation of epidermal growth factor receptor/extracellular signal regulated kinase pathways. J Biol Chem. 2004;279(11):9733-42. https:/doi.org/10.1074/jbc.M311400200.

48. Nakahira K, Morita A, Kim NS, Yanagihara I. Phosphorylation of FOXP3 by LCK downregulates MMP9 expression and represses cell invasion. PLoS One. 2013:8(10):e77099. https://doi.org/10.1371/journal.pone.0077099.

49. van Roosmalen W, le Dévédec SE, Golani O, Smid M, Pulyakhina I, Timmermans AM, et al. Tumor cell migration screen identifies SRPK1 as breast cancer metastasis determinant. J Clin Invest. 2015;125(4):1648-64. https://doi.org/10.1172/JCl74440.

50. Zepecki JP, Snyder KM, Moreno MM, Fajardo E, Fiser A, Ness J, et al. Regulation of human glioma cell migration, tumor growth, and stemness gene expression using a Lck targeted inhibitor. Oncogene. 2019;38(10): 1734-50. https://doi.org/10.1038/s41388-018-0546-z.

51. Ness JK, Snyder KM, Tapinos N. Lck tyrosine kinase mediates beta1-integrin signalling to regulate Schwann cell migration and myelination. Nat Commun. 2013:4(1):1912. https://doi.org/10.1038/ncomms2928.

52. Burchat A, Borhani DW, Calderwood DJ, Hirst GC, Li B, Stachlewitz RF. Discovery of A-770041, a src-family selective orally active Ick inhibitor that prevents organ allograft rejection. Bioorg Med Chem Lett. 2006;16(1):11822. https://doi.org/10.1016/j.bmcl.2005.09.039.

53. Stachlewitz RF, Hart MA, Bettencourt B, Kebede T, Schwartz A, Ratnofsky SE, et al. A-770041, a novel and selective small-molecule inhibitor of Lck, prevents heart allograft rejection. J Pharmacol Exp Ther. 2005;315(1):36-41. https://doi.org/10.1124/jpet.105.089169.

54. Lombardo LJ, Lee FY, Chen P, Norris D, Barrish JC, Behnia K, et al. Discovery of N-(2-chloro-6-methyl- phenyl)-2-(6-(4-(2-hydroxyethyl)- piperazin-1-yl)-2- methylpyrimidin-4- ylamino)thiazole-5-carboxamide (BMS-354825), a dual Src/Abl kinase inhibitor with potent antitumor activity in preclinical assays. Med Chem. 2004;47(27):6658-61. https://doi.org/10.1021/jm049486a.

55. Caswell DR, Swanton C. The role of tumour heterogeneity and clonal cooperativity in metastasis, immune evasion and clinical outcome. BMC Med. 2017;15(1):133. https://doi.org/10.1186/s12916-017-0900-y.

56. Harashima N, Tanaka K, Sasatomi T, Shimizu K, Miyagi Y, Yamada A, et al. Recognition of the Lck tyrosine kinase as a tumor antigen by cytotoxic $T$ lymphocytes of cancer patients with distant metastases. Eur J Immunol. 2001;31(2):323-32. https://doi.org/10.1002/1521-4141(200102)31:2<323::AIDIMMU323>3.0.CO;2-0.

57. Mayer K, Ballhausen W. An essential cis-acting element of the Ick-3' promoter regulates the expression of p56(lck) in metastatic colorectalcancer cells. Int J Oncol. 1993;3(2):369-73. https://doi.org/10.3892/ijo.3.2.369.

58. Straus DB, Weiss A. Genetic evidence for the involvement of the Ick tyrosine kinase in signal transduction through the T cell antigen receptor. Cell. 1992; 70(4):585-93. https://doi.org/10.1016/0092-8674(92)90428-F.

59. Li X, Xu Z, du W, Zhang Z, Wei Y, Wang H, et al. Aiolos promotes anchorage independence by silencing p66Shc transcription in cancer cells. Cancer Cell. 2014;25(5):575-89. https://doi.org/10.1016/j.ccr.2014.03.020.

60. Lopez-Colome AM, et al. Paxillin: a crossroad in pathological cell migration. J Hematol Oncol. 2017;10(1):50. https://doi.org/10.1186/s13045-017-0418-y.

61. Adams D. Keratinization of the oral epithelium. Ann R Coll Surg Engl. 1976; 58(5):351-8.

62. Rogers MA, Edler L, Winter H, Langbein L, Beckmann I, Schweizer J. Characterization of new members of the human type II keratin gene family and a general evaluation of the keratin gene domain on chromosome 12q13.13. J Invest Dermatol. 2005;124(3):536-44. https://doi.org/10.1111/j. 0022-202X.2004.23530.x.

63. Ishay-Ronen D, et al. Gain Fat-Lose Metastasis: Converting Invasive Breast Cancer Cells into Adipocytes Inhibits Cancer Metastasis. Cancer Cell. 2019; 35(1):17-32.e6.

64. Arcaroli JJ, Touban BM, Tan AC, Varella-Garcia M, Powell RW, Eckhardt SG, et al. Gene array and fluorescence in situ hybridization biomarkers of activity of saracatinib (AZD0530), a Src inhibitor, in a preclinical model of colorectal cancer. Clin Cancer Res. 2010;16(16):4165-77. https://doi.org/10.11 58/1078-0432.CCR-10-0066.

65. Chan CM, Jing X, Pike LA, Zhou Q, Lim DJ, Sams SB, et al. Targeted inhibition of Src kinase with dasatinib blocks thyroid cancer growth and metastasis. Clin Cancer Res. 2012;18(13):3580-91. https://doi.org/10.1158/1 078-0432.CCR-11-3359.

66. Heilmann T, Rumpf AL, Roscher M, Tietgen M, Will O, Gerle M, et al. Dasatinib prevents skeletal metastasis of osteotropic MDA-MB-231 cells in a xenograft mouse model. Arch Gynecol Obstet. 2020;301(6):1493-502. https://doi.org/10.1007/s00404-020-05496-4.

67. Levitt JM, Yamashita H, Jian W, Lerner SP, Sonpavde G. Dasatinib is preclinically active against Src-overexpressing human transitional cell carcinoma of the urothelium with activated Src signaling. Mol Cancer Ther. 2010;9(5):1128-35. https://doi.org/10.1158/1535-7163.MCT-10-0096.

68. Morton JP, Karim SA, Graham K, Timpson P, Jamieson N, Athineos D, et al. Dasatinib inhibits the development of metastases in a mouse model of pancreatic ductal adenocarcinoma. Gastroenterology. 2010;139(1):292-303. https://doi.org/10.1053/j.gastro.2010.03.034.

69. Trevino JG, Summy JM, Lesslie DP, Parikh NU, Hong DS, Lee FY, et al. Inhibition of SRC expression and activity inhibits tumor progression and metastasis of human pancreatic adenocarcinoma cells in an orthotopic nude mouse model. Am J Pathol. 2006;168(3):962-72. https://doi.org/10.23 53/ajpath.2006.050570.

70. Zhang S, Huang WC, Zhang L, Zhang C, Lowery FJ, Ding Z, et al. SRC family kinases as novel therapeutic targets to treat breast cancer brain metastases. Cancer Res. 2013;73(18):5764-74. https://doi.org/10.1158/0008-5472.CA $\mathrm{N}-12-1803$.

71. Araujo JC, Trudel GC, Saad F, Armstrong AJ, Yu EY, Bellmunt J, et al. Docetaxel and dasatinib or placebo in men with metastatic castration-resistant prostate cancer (READY): a randomised, double-blind phase 3 trial. Lancet Oncol. 2013; 14(13):1307-16. https://doi.org/10.1016/S1470-2045(13)70479-0.

72. Arcaroli J, Quackenbush K, Dasari A, Powell R, McManus M, Tan AC, et al. Biomarker-driven trial in metastatic pancreas cancer: feasibility in a multicenter study of saracatinib, an oral Src inhibitor, in previously treated pancreatic cancer. Cancer Med. 2012;1(2):207-17. https://doi.org/10.1002/ca m4.27. 
73. Chee CE, Krishnamurthi S, Nock CJ, Meropol NJ, Gibbons J, Fu PF, et al. Phase II study of dasatinib (BMS-354825) in patients with metastatic adenocarcinoma of the pancreas. Oncologist. 2013;18(10):1091-2. https:// doi.org/10.1634/theoncologist.2013-0255.

74. Danson S, Mulvey MR, Turner L, Horsman J, Escott KJ, Coleman RE, et al. An exploratory randomized-controlled trial of the efficacy of the Src-kinase inhibitor saracatinib as a novel analgesic for cancer-induced bone pain. J Bone Oncol. 2019;19:100261. https://doi.org/10.1016/j.jbo.2019.100261.

75. Evans TRJ, van Cutsem E, Moore MJ, Bazin IS, Rosemurgy A, Bodoky G, et al. Phase 2 placebo-controlled, double-blind trial of dasatinib added to gemcitabine for patients with locally-advanced pancreatic cancer. Ann Oncol. 2017;28(2):354-61. https://doi.org/10.1093/annonc/mdw607.

76. Gangadhar TC, Clark Jl, Karrison T, Gajewski TF. Phase II study of the SrC kinase inhibitor saracatinib (AZD0530) in metastatic melanoma. Investig New Drugs. 2013;31(3):769-73. https://doi.org/10.1007/s10637-012-9897-4.

77. Gucalp A, Sparano JA, Caravelli J, Santamauro J, Patil S, Abbruzzi A, et al. Phase II trial of saracatinib (AZD0530), an oral SRC-inhibitor for the treatment of patients with hormone receptor-negative metastatic breast cancer. Clin Breast Cancer. 2011;11(5):306-11. https://doi.org/10.1016/j.clbc.2 011.03.021.

78. Herold Cl, Chadaram V, Peterson BL, Marcom PK, Hopkins J, Kimmick GG, et al. Phase II trial of dasatinib in patients with metastatic breast cancer using real-time pharmacodynamic tissue biomarkers of Src inhibition to escalate dosing. Clin Cancer Res. 2011;17(18):6061-70. https://doi.org/10.11 58/1078-0432.CCR-11-1071.

79. Kalinsky K, Lee S, Rubin KM, Lawrence DP, lafrarte AJ, Borger DR, et al. A phase 2 trial of dasatinib in patients with locally advanced or stage IV mucosal, acral, or vulvovaginal melanoma: a trial of the ECOG-ACRIN Cancer research group (E2607). Cancer. 2017;123(14):2688-97. https://doi.org/10.1 002/cncr.30663.

80. Mackay HJ, Au HJ, McWhirter E, Alcindor T, Jarvi A, MacAlpine K, et al. A phase II trial of the Src kinase inhibitor saracatinib (AZD0530) in patients with metastatic or locally advanced gastric or gastro esophageal junction (GEJ) adenocarcinoma: a trial of the PMH phase II consortium. Investig New Drugs. 2012;30(3):1158-63. https://doi.org/10.1007/s10637-011-9650-4.

81. Ocana A, Gil-Martin M, Antolín S, Atienza M, Montaño Á, Ribelles N, et al. Efficacy and safety of dasatinib with trastuzumab and paclitaxel in first line HER2-positive metastatic breast cancer: results from the phase II GEICAM/ 2010-04 study. Breast Cancer Res Treat. 2019;174(3):693-701. https://doi. org/10.1007/s10549-018-05100-z.

82. Posadas EM, Ahmed RS, Karrison T, Szmulewitz RZ, O'Donnell PH, Wade JL III, et al. Saracatinib as a metastasis inhibitor in metastatic castration-resistant prostate cancer: A University of Chicago phase 2 consortium and DOD/PCF prostate Cancer clinical trials consortium study. Prostate. 2016;76(3):286-93. https://doi.org/10.1002/pros.23119.

83. Powles T, Brown J, Larkin J, Jones R, Ralph C, Hawkins R, et al. A randomized, double-blind phase II study evaluating cediranib versus cediranib and saracatinib in patients with relapsed metastatic clear-cell renal cancer (COSAK). Ann Oncol. 2016;27(5):880-6. https://doi.org/10.1093/a nnonc/mdw014

84. Pusztai L, Moulder S, Altan M, Kwiatkowski D, Valero V, Ueno NT, et al. Gene signature-guided dasatinib therapy in metastatic breast cancer. Clin Cancer Res. 2014;20(20):5265-71. https://doi.org/10.1158/1078-0432.CCR-14-0800.

85. Schott AF, Barlow WE, van Poznak CH, Hayes DF, Moinpour CM, Lew DL, et al. Phase II studies of two different schedules of dasatinib in bone metastasis predominant metastatic breast cancer: SWOG S0622. Breast Cancer Res Treat. 2016;159(1):87-95. https://doi.org/10.1007/s10549-016-3911-z.

86. Fury MG, Baxi S, Shen R, Kelly KW, Lipson BL, Carlson D, et al. Phase II study of saracatinib (AZD0530) for patients with recurrent or metastatic head and neck squamous cell carcinoma (HNSCC). Anticancer Res. 2011;31(1):249-53.

87. Brooks HD, Glisson BS, Bekele BN, Johnson FM, Ginsberg LE, el-Naggar A, et al. Phase 2 study of dasatinib in the treatment of head and neck squamous cell carcinoma. Cancer. 2011;117(10):2112-9. https://doi.org/10.1 002/cncr.25769.

88. Stabile LP, Egloff AM, Gibson MK, Gooding WE, Ohr J, Zhou P, et al. IL6 is associated with response to dasatinib and cetuximab: phase II clinical trial with mechanistic correlatives in cetuximab-resistant head and neck cancer. Oral Oncol. 2017;69:38-45. https://doi.org/10.1016/j.oraloncology.2017.03. 011.

89. Imai N, Harashima N, Ito M, Miyagi Y, Harada M, Yamada A, et al. Identification of Lck-derived peptides capable of inducing HLA-A2-restricted and tumor-specific CTLs in cancer patients with distant metastases. Int J Cancer. 2001;94(2):237-42. https://doi.org/10.1002/ijc.1461.

90. Matsueda S, Itoh K, Shichijo S. Antitumor activity of antibody against cytotoxic T lymphocyte epitope peptide of lymphocyte-specific protein tyrosine kinase. Cancer Sci. 2018;109(3):611-7. https://doi.org/10.1111/cas.13 522.

\section{Publisher's Note}

Springer Nature remains neutral with regard to jurisdictional claims in published maps and institutional affiliations.
Ready to submit your research? Choose BMC and benefit from:

- fast, convenient online submission

- thorough peer review by experienced researchers in your field

- rapid publication on acceptance

- support for research data, including large and complex data types

- gold Open Access which fosters wider collaboration and increased citations

- maximum visibility for your research: over $100 \mathrm{M}$ website views per year

At BMC, research is always in progress.

Learn more biomedcentral.com/submissions 